IZA DP No. 6255

Racial and Ethnic Inequality in Employer Provided Fringe Benefits

Wallace Mok

Zahra Siddique

December 2011 


\title{
Racial and Ethnic Inequality in Employer Provided Fringe Benefits
}

\author{
Wallace Mok \\ Chinese University of Hong Kong \\ Zahra Siddique \\ $I Z A$
}

\section{Discussion Paper No. 6255 \\ December 2011}

\author{
IZA \\ P.O. Box 7240 \\ 53072 Bonn \\ Germany \\ Phone: +49-228-3894-0 \\ Fax: +49-228-3894-180 \\ E-mail: iza@iza.org
}

\begin{abstract}
Any opinions expressed here are those of the author(s) and not those of IZA. Research published in this series may include views on policy, but the institute itself takes no institutional policy positions.

The Institute for the Study of Labor (IZA) in Bonn is a local and virtual international research center and a place of communication between science, politics and business. IZA is an independent nonprofit organization supported by Deutsche Post Foundation. The center is associated with the University of Bonn and offers a stimulating research environment through its international network, workshops and conferences, data service, project support, research visits and doctoral program. IZA engages in (i) original and internationally competitive research in all fields of labor economics, (ii) development of policy concepts, and (iii) dissemination of research results and concepts to the interested public.
\end{abstract}

IZA Discussion Papers often represent preliminary work and are circulated to encourage discussion. Citation of such a paper should account for its provisional character. A revised version may be available directly from the author. 


\section{ABSTRACT}

\section{Racial and Ethnic Inequality in Employer Provided Fringe Benefits}

We examine racial and ethnic inequality in offers of employer provided fringe benefits (health insurance, life insurance and pension). Restricting to full-time workers in the private sector, we find that African Americans are significantly less likely to get fringe benefit offers than non-Hispanic whites after we control for individual differences in age and youth characteristics that matter for labor market success using the 1979 cohort of the National Longitudinal Survey of Youth. We do not find ethnic differences in the 1979 cohort or racial/ethnic differences in the 1997 cohort to be significantly large after controlling for individual differences in age and youth characteristics. Irrespective of race, ethnicity, gender or cohort, we always find that older workers are more likely to get fringe benefit offers as are workers with higher cognitive ability and years of education at age 22 . We find that the crosssections from the 1979 cohort of the National Longitudinal Survey of Youth have more fringe benefit offers than cross-sections from the 1997 cohort. A large part of the difference across cohorts can be explained by the older age profile of cross-sections from the 1979 cohort. Some part of the difference across cohorts can also be explained by differences in family background characteristics, particularly changing family structures which are important for non-Hispanic whites and for African American men. Improvements in cognitive ability and years of education at age 22 for the 1997 cohort increase the unexplained difference in fringe benefit offers across the two cohorts for women (irrespective of race or ethnicity), but not for men.

JEL Classification: I11, J15, J32

Keywords: economics of minorities and races, non-wage labor costs and benefits

Corresponding author:

Zahra Siddique

IZA

P.O. Box 7240

53072 Bonn

Germany

E-mail: siddique@iza.org

\footnotetext{
*We are grateful to Luojia Hu, Bruce Meyer, Andrew Oswald, Gerard Pfann, Christopher Taber, Basit Zafar and seminar participants at the IZA Brownbag seminar for comments. All errors are our own.
} 


\section{Introduction}

There is a well established literature in economics which studies fringe benefits as well as their relationship with wages in the labor market, as described in the theory of equalizing differences. ${ }^{1}$ However, there is less work studying the differences in fringe benefits across different groups defined by gender, race and ethnicity. ${ }^{2}$ Our work contributes to the literature by studying differences in fringe benefits offered by employers to their workers across groups using detailed longitudinal data from the 1979 and 1997 cohorts of the National Longitudinal Survey of Youth. The use of these data allows us to control for individual differences in youth characteristics such as family background, cognitive ability and education which have an impact on later labor market success, specifically the quality of jobs workers engage in as defined by the presence or absence of fringe benefits.

Workers may trade fringe benefits for higher wages or vice versa with productivity held constant. For different productivity levels, demand for fringe benefits should go up for high skill workers as wages increase since fringe benefits are a normal good. High skill workers are also more likely to demand fringe benefits because of the progressive nature of the tax system. We control for skill differences across groups by using cognitive ability and years of schooling at age 22 as control variables in our analysis. Additional characteristics that we control for are family background variables such as mother's years of education, father's years of education and whether or not the individual was living with both biological parents at age 14. Family background variables influence skill acquisition and may also play an important role in whether or not a worker is offered a fringe benefit in the labor market. These youth characteristics have been shown in the literature to vary across different racial and ethnic groups, with African Americans and Hispanics generally doing worse than non-Hispanic whites. ${ }^{3}$ However, the role of these characteristics in the quality of jobs workers engage in as defined by the presence or absence of fringe benefits has not been examined in the literature.

Recent work by Altonji, Bharadwaj and Lange[1] has also documented the changing characteristics of American Youth by comparing youth characteristics across the 1979 and 1997 cohorts of the National Longitudinal Survey of Youth. They find that skills of all groups have improved over time, African Americans and Hispanics have gained in skills relative to non-Hispanic whites and women have gained relative to men. Parental education has improved for all groups, with the 1997 cohort having more highly educated parents than the 1979 cohort. Family structure variables such as whether or not an individual was living with both

\footnotetext{
${ }^{1}$ See Rosen[17] and Woodbury[20].

${ }^{2}$ Exceptions are Hersch and White-Means[7], Levy[11] and Solberg and Laughlin[18]. Our work is similar in spirit to Hersch and White-Means[7] who study racial inequality in both wages and total compensation (wages plus fringe benefits) using the 1988 CPS Survey of Employee Benefits, and find that 'white men are more likely to be covered by fringe benefits than are women and black men.' They also find that the gaps in earnings of private employees are only slightly affected when total compensation is used as the benchmark. However, due to limitation of data, it may be premature to conclude that there exists racial discrimination in also the awarding of fringe benefits.

${ }^{3}$ See Fryer[5], Neal and Johnson[13] and Neal[15].
} 
biological parents at age 14 are, however, worse for the 1997 cohort compared to the 1979 cohort. This is the result of fewer individuals of the 1997 cohort living with their biological father. Our work also examines the impact of changing youth characteristics across the 1979 and 1997 cohorts of the National Longitudinal Survey of Youth on fringe benefit offers, something which has also not yet been examined in the literature.

Restricting to full-time workers in the private sector, we find that African American men of the 1979 cohort of the National Longitudinal Survey of Youth are less likely to be offered fringe benefits such as health insurance, life insurance and pensions than non-Hispanic whites after we have controlled for age and youth characteristics. This finding is important since it indicates a very real disadvantage faced by African American men in workplace amenities, not just wages. However, we do not find that African American men are significantly less likely to be offered fringe benefits than non-Hispanic whites after controlling for age and youth characteristics in the recent 1997 cohort.

For women, we find smaller gaps (compared to men) in fringe benefit offers across race, with African American women being less likely to receive fringe benefit offers than non-Hispanic white women once we have controlled for age and youth characteristics. These gaps also disappear for the later 1997 cohort of the National Longitudinal Survey of Youth.

Across ethnicity, we do not find that Hispanics have significantly fewer fringe benefit offers than nonHispanics once we control for age and youth characteristics.

Our most consistent finding is that workers are significantly more likely to be offered fringe benefits as they get older. More skilled workers (with higher cognitive scores and years of schooling at age 22) are significantly more likely to get fringe benefit offers. This is the case for all race/ethnic/gender groups and for either the 1979 or 1997 cohort.

We find that the 1979 cohort cross-sections have more fringe benefit offers than the 1997 cohort crosssections. A large part of the difference across cohorts can be explained by the older age profile of the 1979 cohort cross-sections. Some part of the difference across cohorts can also be explained by differences in family background characteristics, particularly changing family structures which are important for nonHispanic whites and for African American men. Higher skills of the 1997 cohort cross-sections increase the unexplained difference in fringe benefit offers across cohorts for women (irrespective of race or ethnicity) but not for men. The unexplained difference in fringe benefit offers across cohorts remains substantial and of interest for future research.

In section 2, we begin with a discussion of the empirical facts about fringe benefits in the United States. In section 3, we describe the data we use. In section 4, we provide a motivation for our work by giving unconditional racial and ethnic gaps in fringe benefit offers over the lifetime of the 1979 cohort of the National Longitudinal Survey of Youth. In section 5, we describe differences in youth characteristics across race and ethnicity as well as across cohorts and the role of these characteristics in fringe benefit offers. 


\section{Fringe Benefits}

Relative to the vast number of studies regarding how wages are determined, the literature on non-wage labor compensation is smaller, especially on fringe benefits. Using data from a sample of white men in the Current Population Survey, Chung[3] documents the changes in wages and fringe benefits between 1987 and 1994, and concludes that 'analysis based exclusively on wages tends to overestimate inequality among the skilled, underestimate inequality among the less skilled, and understate inequality in the labor market.'

Non-wage benefits have become a more important part of the employee's overall labor compensation package. Table 1 shows that the fraction of employee total compensation attributed to fringe benefits (exclude legally required benefits) has been rising over the last decade. In 1995, fringe benefits constituted just 20 percent of the average employee's total compensation, but this had increased to 23 percent by 2011 . There are several reasons why employers choose to provide fringe benefits and why employees choose to accept them. First, in accordance with the 1943 Internal Revenue Code, compensation in the form of fringe benefits is tax deductible for the employer. Second, for health insurance, employees may find it cheaper to purchase health insurance through their employers selected schemes. Other than public health insurance which is not universal, those who cannot or cannot afford to purchase health insurance may find employerprovided health insurance the only way of getting insured, especially those with chronic or preexisting health conditions. Third, if the productivity of a company is positively correlated with the health of its workforce, then providing health insurance is certainly important to the firm's profitability. Fourth, fringe benefits may give an impression to the employees that by losing their job, they will lose more than their wages. Those whose entire family is covered by employer-provided health insurance may find it especially costly to quit their job. Since the cost to the employer in providing these benefits is lower due to risk pooling (or group discounts), it may be viewed as a cost-effective device.

Table 1 also show how employer-provided health insurance has become a rising cost to the employer over the last decade. In 1995 employer-provided health insurance constituted 6.6 percent of the hourly average cost, but had risen to 8.4 percent by 2011. Health insurance is also a significant part of all fringe benefits paid, being 37 percent of all fringe benefits by 2011. It is also important to note that the cost of an average health insurance policy has risen significantly in the last 10 years. According to data from the Kaiser/HRET Survey of Employer Sponsored Health Benefits[8][9] the average annual premium for single health insurance coverage has more than doubled between 1999 and 2008, rising from 2,916 dollars to 4,704 dollars in nominal terms. Average annual premiums for family coverage have also risen by a similar percentage, from 5,791 dollars in 1999 to 12,680 dollars in 2008. In terms of the costs borne by the 
employers, the average per-employee health insurance premium contribution has risen from 1,878 dollars (86 percent of the total premium) in 1999, to 3,983 dollars (85 percent of the total premium) in 2008. Thus, employer provided health insurance has become more valuable to the average employee, and represents a larger proportion of his total compensation over the last decade.

For employer provided pension, it amounts to about 3-5 percent of the employee's total compensation. Columns 5-6 of table 1 also show that the cost to the employer of providing pension has increased, from $\$ 0.71$ in 1995 (per hour worked) to $\$ 1.36$ in 2011. As a fraction of total fringe benefits offered to the employees, the cost of pension has remained steady at around 17-21 percent.

\section{Data}

We use the 1979 and 1997 cohorts of the National Longitudinal Survey of Youth (NLSY79 and NLSY97 respectively). The NLSY79 is a panel study of a sample of 12,686 young men and women who were 14 to 22 years old when they were first interviewed in 1979. Since then, they have been re-interviewed yearly from 1979 to 1994, and bi-annually since 1996.

The NLSY97 is a panel study with a sample of about 9,000 youths (a cross-sectional nationally representative sub-sample of 6,748 respondents and a supplemental sample of 2,236 respondents designed to over sample Hispanic or Latino and black people) who were 12-16 years of age as of December of 1996 . The first round of interviews was conducted in 1997, and individuals were followed annually. Up to 13 rounds of interviews have been conducted as of 2009. Similar to the NLSY79, the survey collects extensive information on labor market experience, educational experiences, health issues, family issues, as well as information on the participation of government programs.

A particularly attractive feature of using the NLSY79 and NLSY97 is that they provide a proxy for the individual's cognitive ability- the Armed Forces Qualification Test (AFQT) score. In 1980, over 90 percent of the NLSY79 respondents were given a set of 10 tests from the Armed Services Vocational Aptitude Battery (ASVAB). Formally, the tests in the ASVAB consist of (1) general science, (2) arithmetic reasoning, (3) word knowledge, (4) paragraph comprehension, (5) numerical operations, (6) coding speed, (7) auto and shop information, (8) mathematical knowledge, (9) mechanical comprehension, and (10) electronics information. A subset of four of these tests constitutes the AFQT. The AFQT score is used by the military services to screen applicants and thereby assign various jobs within the military. In the summer of 1997 through the spring of 1998, most of the NLSY97 round 1 respondents participated in the ASVAB. To ensure comparability of the AFQT scores in both cohorts, we make use of the adjusted AFQT scores provided by Altonji, Bharadwaj and Lange[1]. ${ }^{4}$ The use of the AFQT score as a measure of the cognitive ability of the

\footnotetext{
${ }^{4}$ Altonji, Bharadwaj and Lange[1] converted the scores in NLSY97 by first transforming them into a paper and pencil test score, then adjusting them to account for the age at which individuals took the test.
} 
individual has been fairly widespread in economics and sociology. ${ }^{5}$

The questions in these surveys regarding employer-provided fringe benefits are phrased as follows: Did the employer MAKE AVAILABLE to you (type of benefit)? The NLSY thus provides information on whether or not an individual received an offer of fringe benefit from the employer. ${ }^{6}$

\section{Motivation- Gaps in Fringe Benefit Offers across Race and Ethnicity}

The motivation for our work comes from differences in fringe benefit offers across demographic groups (nonHispanic whites, African Americans, and Hispanics) within the NLSY79 for each fringe benefit of health insurance, life insurance, and pension.

We plot locally weighted regressions of fringe benefit offers conditional on age using pooled cross-sections of the NLSY79 from 1979 to 2008. We use observations for individuals who were twenty two or older and employed full-time (working more than thirty five hours per week) in the private sector. Figure 4.1 graphically illustrates the estimation results (separately for men and women).

For the male sub-sample (sub-figures (a), (c) and (e) of figure 4.1) we observe the following: First, fringe benefit offers (for health insurance, life insurance and pensions) are always higher for non-Hispanic white men than for African American men or Hispanic men of the same age. Second, each type of fringe benefits is more likely to be offered to older workers, across all ages. Third, the likelihood of health insurance offers varies between 0.70 and 0.95 , for life insurance it varies between 0.55 and 0.85 , and for pensions they vary between 0.30 and 0.80 . The differences in fringe benefit offers across racial and ethnic groups for men remain fairly persistent as workers approach the peak of their lifetime earnings profile during the mid to late forties.

For the female sub-sample (sub-figures (b), (d) and (f) of figure 4.1) we observe the following: First, fringe benefit offers (for health insurance and life insurance) are generally higher for non-Hispanic white women than for African American women and Hispanic women of the same age. Second, fringe benefit offers are higher for older workers. Third, the fraction of workers offered health insurance varies between 0.70 and 0.90 , for life insurance it varies between 0.55 and 0.80 , and for pensions it varies between 0.50 and 0.80 .

We also observe that the racial gap in fringe benefit offer rate for women is smaller than that for men. At the same time the ethnic gap in fringe benefit offer rate for women is larger, and increases for older workers older Hispanic women actually receive fewer fringe benefit offers than younger Hispanic women. These figures

\footnotetext{
${ }^{5}$ See Neal and Johnson[13], Neal[15], Fryer[5] and Altonji, Bharadwaj and Lange[1].

${ }^{6}$ As discussed in Mok and Siddique[12], racial differences in take-up behavior of fringe benefits can affect the validity in using the offer rate as a measure of inequality. If non-takeup of fringe benefits arises mostly due to endogenous reasons, then the use of the offer rate is more appropriate than that of the coverage rate. For health insurance, Mok and Siddique[12] find that, using data from the Survey of Income and Program Participation, 'ineligibility due to the type of employment' is the primary exogenous reason for non-takeup. Therefore, we believe that by restricting our attention to only on those who are working full-time, most of the non-takeup will be due to endogenous reasons, thus the differences in the offer rate is a better measure of inequality.
} 
document inequality in fringe benefit offers particularly across non-Hispanic white and African American men, and across non-Hispanic white and Hispanic women. The differences across groups are constant or increasing for older workers.

For comparison, we also examine the gap in fringe benefit offers across racial and ethnic groups for the younger NLSY97 cohort for each fringe benefit of health insurance, life insurance, and pensions. We repeat our analysis using pooled cross-sections of the NLSY97 from 1997 to 2009 (with the same restrictions), with results reported in figure 4.2 separately for men and women. Effectively, given the age profile of the NLSY97 cohort, this means we use observations from 2001 to 2009 cross-sections only.

For the male sub-sample we observe very similar patterns as in the NLSY79, except that offers of health insurance vary between 0.55 and 0.80 , for life insurance they vary between 0.30 and 0.60 , and for pensions they vary between 0.30 and 0.65 . Note that offer rates for the NLSY97 cohort are sometimes lower than the smallest value of mean fringe benefit offers conditional on age for the same fringe benefit in the NLSY79 cohort. Across groups, differences in offers of health insurance, life insurance and pensions between nonHispanic white and African American men increase as the men approach their late twenties. The ethnic gap in fringe benefit offers is quite small for men.

For women in the NLSY97, it is worth to note that the racial gap in offers of health insurance is large but closes over time, for life insurance this racial gap is smaller but also closes over time, for pension plans the racial gap is large but again tends to close for older women. The ethnic gap in health insurance offers is non-existent, for life insurance the gap increases for older women while for pensions it is large for women between twenty four and twenty eight, but small otherwise.

This section provides the motivation for the rest of our work. We identify patterns of inequality in fringe benefit offers across race and ethnicity separately for men and women of similar ages. These patterns suggest the existence of inequality, putting African Americans and Hispanics at a disadvantage in workplace amenities in the NLSY79 cohort. In addition, there are fewer fringe benefit offers for the younger NLSY97 cohort in comparison to the NLSY79 cohort. This raises a number of interesting questions to which we now turn to: Can differences in characteristics explain the patterns of inequality in fringe benefit offers across demographic groups? Can differences in characteristics across cohorts explain the low offer rates for fringe benefits in the NLSY97 cohort compared to the NLSY79 cohort?

\section{$5 \quad$ Racial and Ethnic Inequality in Fringe Benefits}

\subsection{Racial and Ethnic Differences in Characteristics}

In this section we briefly summarize characteristics of workers before they enter the labor market which have an impact on labor market success- these are parental education, cognitive ability and schooling. How 
these characteristics affect labor market success has been discussed extensively in the literature. We will also discuss how these characteristics have changed between our two NLSY cohorts. The definition of parental education is straight-forward. For skills, we use standardized AFQT scores (where the scores are standardized by age) as our measure of cognitive ability and years of schooling at age 22 .

The descriptive statistics of these characteristics are presented in table A.1, Panel 1 (NLSY79) and Panel 2 (NLSY97). For the NLSY79, on average, the racial difference in the cognitive skill measure as given by standardized AFQT score is larger for non-Hispanic white men relative to African American men and smaller for non-Hispanic white men relative to Hispanic men. Years of schooling at age 22 are higher for non-Hispanic white men, on average, in comparison to African American men but the magnitude of the difference is not large given the variation in years of schooling within groups. The difference in mean years of schooling at age 22 is larger for non-Hispanic white relative to Hispanic men. Non-Hispanic white men tend to do better on skill measures in comparison to African American and Hispanic men at the mean. The mean years of schooling of fathers of non-Hispanic white men are higher than they are for African American men. The ethnic gap for this family background measure is even larger, with non-Hispanic white men having fathers with, on average, higher years of schooling than Hispanics. Mothers' years of schooling show a similar pattern across racial groups but, on average, mothers of African American men have higher years of schooling than the fathers. There is also a larger ethnic gap in this family background measure, with mean years of schooling of mothers of non-Hispanic white men being higher than of Hispanic men. The mean years of schooling for both mothers and fathers of Hispanic men are particularly low, at just above eight years. While mothers of African American men had higher years of schooling than fathers of African American men, mothers of Hispanic men have lower years of schooling than fathers of Hispanic men. The fraction of men who live with both parents at age fourteen is highest for non-Hispanic white men, it is almost twenty percent lower for African American men. The ethnic gap in this fraction is not large, with seventy five percent of non-Hispanic whites living with both parents and just seventy four percent of Hispanics living with both parents at age fourteen.

For women, there is a small racial gap in mean years of schooling at age 22 but the variation in years of schooling at age 22 is larger for non-Hispanic white women than for African American women. However, non-Hispanic white women have greater mean years of schooling at age 22 than do Hispanic women. There is also a racial and ethnic gap in the standardized AFQT scores for women, with non-Hispanic white women scoring higher, on average, on standardized AFQT scores than African American and Hispanic women. As was the case for men, the racial gap at the mean is larger across race than across ethnicity. Again as was the case for men, non-Hispanic white women tend to do better than African American and Hispanic women on skill measures which may impact later labor market outcomes. The patterns in family background characteristics for our female sample are very similar to those for men of the NLSY79 cohort. The mean 
years of schooling for fathers of non-Hispanic white women are higher than for fathers of African American women. There is an even larger gap across ethnicity, with mean years of schooling for fathers of non-Hispanic white women being higher than for fathers of Hispanic women. Additionally the mean years of schooling for mothers of white women are higher than mean years of schooling for mothers of African American women. The gap across ethnicity is again larger, with non-Hispanic white women having mothers with higher years of schooling than mothers of Hispanic women. On average, years of schooling are lowest for parents of Hispanic women. Additionally, as was the case for men, while mothers of African American women have higher years of schooling on average than fathers of African American women, the mothers of Hispanic women tend to have lower years of schooling on average than fathers of Hispanic women. The fraction of women who live with both parents at age fourteen is seventy nine percent for non-Hispanic white women and far lower at sixty percent for African American women. There is a smaller ethnic gap in this measure, with seventy five percent of Hispanic women on average living with their parents at age fourteen. For both men and women, family background characteristics are best for non-Hispanic whites and worse in general for African Americans and Hispanics.

In comparison to the NLSY79 cohort the mean values of both standardized AFQT scores and years of schooling at age 22 of the NLSY97 cohort have increased for all groups except for a small decline for African American men. While mean years of schooling for both mothers and fathers have increased for all groups for the NLSY97 cohort compared to the NLSY79 cohort, the fraction of individuals who live with both parents has gone down. While skill measures have improved in the later NLSY97 cohort compared to the NLSY79, non-Hispanic white men continue to have better skill measures, on average, than do African American and Hispanic men. In the NLSY97 cohort, standardized AFQT scores are lower for African American and Hispanic women compared to non-Hispanic white women. As was the case for men and the NLSY79 cohort, the racial gap in AFQT scores is larger than the ethnic gap. Non-Hispanic white women have on average more years of schooling at age 22 than do African American and Hispanic women. Note however that for either race/ethnicity women tend to have more years of schooling at age 22 than men of the same race/ethnicity. Generally, as for men, non-Hispanic white women continue to have better skill measures, on average, than do African American and Hispanic women.

It is also interesting to see that the NLSY97 cohort shows a dramatic improvement in average years of schooling of parents for all groups in comparison to the NLSY79 cohort. Within the male sample, nonHispanic white men have fathers with higher years of schooling on average than African American and Hispanic men. The difference in mean fathers years of schooling is higher across ethnicity than race, with fathers of Hispanic men having the lowest years of schooling on average. Non-Hispanic white men also have mothers with higher years of schooling on average than do African American and Hispanic men. The difference in mothers years of schooling is also wider across ethnicity than across race, with Hispanic men 
having mothers with lowest years of schooling on average. The fraction of men who lived with both their parents at age fourteen has actually dropped in comparison to the NLSY79 cohort. The largest drop occurs for African Americans, with just forty three percent of African American men living with both parents at age fourteen. A far higher fraction of white men were living with both parents at age fourteen, at seventy one percent. The ethnic gap in this measure of family background is not as large, with sixty seven percent of Hispanic men living with both parents at age fourteen.

In terms of the distribution of the AFQT scores across racial and ethnic groups, Figure 5.1.1 documents racial and ethnic differences in standardized AFQT scores and years of schooling at age 22 separately for men and women in the NLSY79. For both men and women the distribution of standardized AFQT scores is close to normal for non-Hispanic white men and women, but negatively skewed for African American as well as Hispanic men and women. The differences in years of schooling at age 22 are smaller across racial and ethnic groups for both men and women than the differences in standardized AFQT scores, with a peak for all groups at twelve years of schooling. Figure 5.1.2 repeats the same exercise for the NLSY97 cohort. The skill distribution of the NLSY97 cohort has improved overall compared to the NLSY79 cohort. The distribution of standardized AFQT scores is now positively skewed for non-Hispanic white men and women. The distribution of standardized AFQT scores is still somewhat negatively skewed for African American and Hispanic men and women but the scores are higher in comparison to those found in the NLSY79. While there have been gains made in skills for all groups, there is still a relative disadvantage of African American and Hispanic men and women in standardized AFQT scores compared to non-Hispanic whites. There is also an improvement in years of schooling at age 22 for all groups in comparison to the 1979 cohort. However, non-Hispanic white men and women still do relatively better in terms of years of schooling at age 22 than do other groups.

\subsection{The Role of Characteristics on Racial and Ethnic Inequality in Fringe Benefits}

To estimate the racial and ethnic gap in fringe benefit offers conditional on age, cognitive ability, education and family background, we estimate a probit on the fringe benefit offer dummy for each fringe benefit, $b_{i} \in\left\{h_{i}, l_{i}, p_{i}\right\}$ (whether or not an individual worker $i$ is offered health insurance, life insurance or a pension plan) on a set of control variables $x_{i}$ interacted with race and ethnicity $\left(a_{i}, e_{i}\right)$. The set of control variables, $x_{i}=\left(a g e_{i}, a f q t_{i}, e d u c_{i}, f_{a m i l y}\right)$, for individual worker $i$ include: age, cognitive ability as measured by standardized AFQT score, years of schooling at age 22 and family background characteristics (years of schooling of the father and mother, whether or not the individual was living with both biological parents at age fourteen).

We carry out these estimations separately for men and women, using first all cross sections of the NLSY79 from 1979 to 2008, restricted to observations where the individual is twenty two or more years of age, and 
working full-time (more than thirty five hours per week) in the private sector. The results are reported in table 5.1. For men, all fringe benefits are less likely to be offered when the individual is African American after we include the complete set of controls interacted with race and ethnicity. The marginal effect on the race dummy is negative and statistically significant. In magnitude it is largest for life insurance, then health insurance and smallest (but still statistically significant) for pensions. The Hispanic dummy is insignificant. Younger men are significantly less likely to receive fringe benefits than older workers, irrespective of race or ethnicity. The age effect is largest in magnitude for pensions. Men with higher AFQT scores and years of schooling are significantly more likely to receive fringe benefit offers, irrespective of race or ethnicity. This effect is largest in magnitude for pensions if we consider schooling, and for life insurance if we consider standardized AFQT score as the skill measure. Among family background variables the most important is whether the male was living with both parents at age fourteen. If the individual was living with both parents at age fourteen then he is statistically significantly more likely to be offered a fringe benefit (in particular if the fringe benefit is health insurance or if he is non-Hispanic white).

African American women are also statistically significantly less likely to receive fringe benefits than comparable non-Hispanic white women, although the magnitude of the racial gap in life insurance and pension offers is smaller than for men. The ethnic gap in fringe benefits is larger for women than for men, Hispanic women receiving fewer offers of fringe benefits than comparable non-Hispanic white women. Younger women are also significantly less likely to be offered a fringe benefit than older women, irrespective of race or ethnicity. As for men, the age effect is strongest for pension offers. Women with higher AFQT scores and years of schooling are also more likely to receive fringe benefit offers, irrespective of race or ethnicity. The most important family background variables are father's years of education (for black women) and whether the individual was living with both parents at age fourteen (for non-Hispanic white women).

The estimations in table 5.1 are a clear indication of the disadvantage faced by African Americans in workplace amenities such as offers of fringe benefits after we have controlled for individual differences in characteristics. The inequality across racial groups could be arising from current or past discrimination by the employer against African Americans in making fringe benefits available or in access to jobs which offer such benefits. Also interesting to note is the absence of such inequality across ethnic groups, and particularly across Hispanic and non-Hispanic white men after we control for age and individual differences in characteristics.

We repeat the same exercise with the NLSY97. ${ }^{7}$ The results are reported in table 5.2. We do not find significantly large gaps either across race or ethnicity in the NLSY97 cohort, once we condition on a full set of controls interacted with race and ethnicity. While the sign of the coefficients on race and ethnicity is not always negative, the estimation of these coefficients is less precise than the NLSY79 given the smaller

\footnotetext{
${ }^{7}$ Our sample restriction effectively limits us to using observations from the 2001 to 2009 cross-sections of the NLSY97.
} 
sample size of the NLSY97 cross-sections compared to the NLSY79 cross-sections. The coefficients on the race dummy are thus neither significantly negative nor positive. For the male sub-sample older workers are more likely to be offered fringe benefits, particularly for the Hispanic and non-Hispanic white men and for pension offers. For the female sub-sample, older workers are also more likely to be offered fringe benefits. Workers with higher AFQT scores and years of schooling are also more likely to be offered fringe benefits for both the male and female sub-samples.

An important result from the probit analysis on fringe benefit offers is the difference across the NLSY79 and NLSY97 cohorts. The next section examines the role of differences in age as well as changes in characteristics in explaining the difference in fringe benefit offers across cohorts.

\subsection{Changes in Fringe Benefits over Time- differences across the NLSY79 and NLSY97 cohorts}

In order to make a comparison of fringe benefit offers across the NLSY79 and NLSY97 cohorts, we start by using a decomposition method at the mean, the Fairlie decomposition[4] which is an extension of the Blinder-Oaxaca decomposition for binary outcomes. Such a decomposition allows us to quantify the relative importance of differences in distributions of observable characteristics (such as age, cognitive ability, years of schooling and family background) with the relative importance of group differences in coefficients (or the effect of these characteristics) across the NLSY79 and NLSY97 cohorts, to mean differences in fringe benefit offers across these cohorts.

Let $b=F(x \widehat{\beta})$ where $F$ is the cumulative distribution function from the standard normal distribution (probit) and $x=($ age, afqt, educ, family). The decomposition in terms of the mean value of the difference in fringe benefit offers for each fringe benefit $b \in\{h, l, p\}$ across the NLSY79 and NLSY97 cohorts is

$$
\bar{b}^{1979}-\bar{b}^{1997}=\left[\sum_{i=1}^{N^{1979}} \frac{F\left(x_{i}^{1979} \widehat{\beta}^{1979}\right)}{N^{1979}}-\sum_{i=1}^{N^{1997}} \frac{F\left(x_{i}^{1997} \widehat{\beta}^{1979}\right)}{N^{1997}}\right]+\left[\sum_{i=1}^{N^{1997}} \frac{F\left(x_{i}^{1997} \widehat{\beta}^{1979}\right)}{N^{1997}}-\sum_{i=1}^{N^{1997}} \frac{F\left(x_{i}^{1997} \widehat{\beta}^{1997}\right)}{N^{1997}}\right]
$$

or equivalently

$$
\bar{b}^{1979}-\bar{b}^{1997}=\left[\sum_{i=1}^{N^{1979}} \frac{F\left(x_{i}^{1979} \widehat{\beta}^{1997}\right)}{N^{1979}}-\sum_{i=1}^{N^{1997}} \frac{F\left(x_{i}^{1997} \widehat{\beta}^{1997}\right)}{N^{1997}}\right]+\left[\sum_{i=1}^{N^{1979}} \frac{F\left(x_{i}^{1979} \widehat{\beta}^{1979}\right)}{N^{1979}}-\sum_{i=1}^{N^{1979}} \frac{F\left(x_{i}^{1979} \widehat{\beta}^{1997}\right)}{N^{1979}}\right]
$$

where $\left(N^{1979}, N^{1997}\right)$ are the sample sizes for NLSY79 cohort and NLSY97 cohorts. The first term in (1) and 
(2) gives the total contribution of group differences in characteristics, $X=($ Age, AFQT, Educ, Family), across cohorts while the second gives the contribution of group differences in coefficients.

We are interested not just in the total contribution of group differences in characteristics $X$ or the first term in (1) and (2), but also in the contribution of components of $X=($ Age, AFQT, Educ, Family) to the gap in fringe benefits across cohorts. Assume initially that both cohorts have the same number of observations $N^{1979}=N^{1997}$. Using coefficient estimates from a pooled sample of NLSY79 and NLSY97 $\widehat{\beta}^{*}$, the independent contribution of Family to the difference in fringe benefit offers for each fringe benefit $b \in\{h, l, p\}$ across cohorts is

$$
\begin{array}{r}
\frac{1}{N^{1997}} \sum_{i=1}^{N^{1997}} F\left(\widehat{\alpha}^{*}+a g e_{i}^{1979} \widehat{\beta}_{A g e}^{*}+e d u c_{i}^{1979} \widehat{\beta}_{E d u c}^{*}+a f q t_{i}^{1979} \widehat{\beta}_{A F Q T}^{*}+\text { family }_{i}^{1979} \widehat{\beta}_{F a m i l y}^{*}\right)- \\
F\left(\widehat{\alpha}^{*}+a g e_{i}^{1979} \widehat{\beta}_{A g e}^{*}+e d u c_{i}^{1979} \widehat{\beta}_{E d u c}^{*}+a f q t_{i}^{1979} \widehat{\beta}_{A F Q T}^{*}+\text { family }_{i}^{1997} \widehat{\beta}_{\text {Family }}^{*}\right)
\end{array}
$$

In the same way the independent contribution of $A F Q T$ and $E d u c$ to the difference in fringe benefit offers for each fringe benefit $b \in\{h, l, p\}$ across cohorts is

$$
\begin{array}{r}
\frac{1}{N^{1997}} \sum_{i=1}^{N^{1997}} F\left(\widehat{\alpha}^{*}+a g e_{i}^{1979} \widehat{\beta}_{\text {Age }}^{*}+e d u c_{i}^{1979} \widehat{\beta}_{E d u c}^{*}+a f q t_{i}^{1979} \widehat{\beta}_{A F Q T}^{*}+\text { family }_{i}^{1997} \widehat{\beta}_{\text {Family }}^{*}\right)- \\
F\left(\widehat{\alpha}^{*}+a g e_{i}^{1979} \widehat{\beta}_{\text {Age }}^{*}+e d u c_{i}^{1997} \widehat{\beta}_{E d u c}^{*}+a f q t_{i}^{1997} \widehat{\beta}_{A F Q T}^{*}+\text { family }_{i}^{1997} \widehat{\beta}_{\text {Family }}^{*}\right)
\end{array}
$$

and the independent contribution of Age to the difference in fringe benefit offers for each fringe benefit $b \in\{h, l, p\}$ across cohorts is

$$
\begin{array}{r}
\frac{1}{N^{1997}} \sum_{i=1}^{N^{1997}} F\left(\widehat{\alpha}^{*}+a g e_{i}^{1979} \widehat{\beta}_{\text {Age }}^{*}+e d u c_{i}^{1997} \widehat{\beta}_{E d u c}^{*}+a f q t_{i}^{1997} \widehat{\beta}_{A F Q T}^{*}+f a m i l y_{i}^{1997} \widehat{\beta}_{F a m i l y}^{*}\right)- \\
F\left(\widehat{\alpha}^{*}+a g e_{i}^{1997} \widehat{\beta}_{A g e}^{*}+e d u c_{i}^{1997} \widehat{\beta}_{E d u c}^{*}+a f q t_{i}^{1997} \widehat{\beta}_{A F Q T}^{*}+\text { family }_{i}^{1997} \widehat{\beta}_{\text {Family }}^{*}\right)
\end{array}
$$

The contribution of different components of $X=($ Age, AFQT, Educ, Family $)$ to the gap in fringe benefit offers across cohorts is equal to the change in average predicted probability from replacing the NLSY97 distribution with the NLSY79 distribution of each $X=$ (Age, AFQT, Educ, Family) while holding the distributions of the other variables constant. Note that the order of switching of variables is important; we deliberately use the order of switching family background variables (mother and father years of schooling, whether living with both parents at age fourteen) first, skill variables (standardized AFQT scores and years 
of schooling at age 22) second and age last which is based on the natural timing of these variables. By using this method, we ensure that the individual contributions from $X=($ Age, AFQT, Educ, Family $)$ together add to the total contribution of group differences in characteristics, as given by the first term of (1) and (2). Standard errors for the individual contributions may be estimated using the delta method. ${ }^{8}$

The sample size for the NLSY79 is far larger than of the NLSY97 so there is a problem in the one-to-one matching needed to estimate the individual contributions of each of $X=($ Age, Educ, AFQT, Family). To get around this problem we first use pooled coefficient estimates to estimate predicted outcome probabilities for each NLSY79 and NLSY97 observation. Then a random sub-sample is drawn from the NLSY79 which is equal in size to the full NLSY97 sample. Each observation in the NLSY79 sub-sample and the full NLSY97 sample is ranked using predicted probabilities and matched based on this ranking. 100 random sub-samples are drawn from the NLSY79, each of these sub-samples is then matched with the NLSY97 sample and separate decomposition results estimated. The mean value from these separate decompositions is then used to approximate the results for the entire NLSY79 sample.

The results are reported in 5.3. As already observed, fewer people in the NLSY97 cohort are offered a fringe benefit than in the NLSY79 cohort. This difference is largest for life insurance $(0.205$ for the pooled sample of men and 0.199 for the pooled sample of women) and smallest for health insurance (0.112 for the pooled sample of men and 0.120 for the pooled sample of women). For pension plans the difference in offer rates is between 0.1 and 0.2 (0.138 for the pooled sample of men and 0.159 for the pooled sample of women). The most important factor explaining the difference in offer rates across cohorts is age. The older age profile of the NLSY79 explains $22 \%$ of the total difference across cohorts for health insurance offers, $12 \%$ of the total difference across cohorts for life insurance offers and $50 \%$ of the total difference across cohorts for pension offers for the pooled sample of men. It explains $19 \%$ of the total difference across cohorts for health insurance offers, $13 \%$ of the total difference across cohorts for life insurance offers and $41 \%$ of the total difference across cohorts for pension offers for the pooled sample of women. As mentioned already, AFQT scores and years of schooling have improved for the NLSY97 cohort in comparison with the NLSY79

\footnotetext{
${ }^{8}$ Rewriting the expression for individual contribution of Family as
}

$$
\hat{D}_{1}=\frac{1}{N^{1997}} \sum_{i=1}^{N^{1997}} F\left(X_{i}^{\text {age }}{ }^{1979} e_{u c c^{1979} \text { afqt }}^{1979} \text { family }^{1979} \widehat{\beta}^{*}\right)-F\left(X_{i}^{\text {age }}{ }^{1979} \text { educ }^{1979} \text { afqt }^{1979} \text { family }^{1997} \widehat{\beta}^{*}\right)
$$

the variance may be approximated as

$$
\operatorname{Var}\left(\hat{D}_{1}\right)=\left(\frac{\delta \hat{D}_{1}}{\widehat{\beta}^{*}}\right)^{\prime} \operatorname{Var}\left(\widehat{\beta}^{*}\right) \frac{\delta \hat{D}_{1}}{\widehat{\beta}^{*}}
$$

with

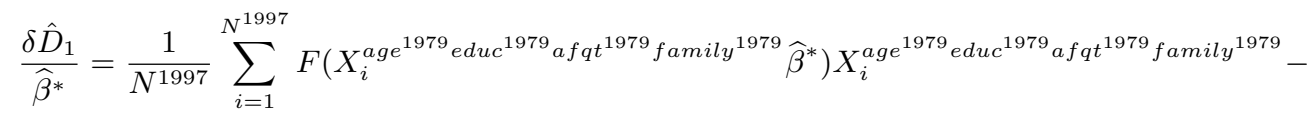

$$
\begin{aligned}
& F\left(X_{i}^{\text {age }}{ }^{1979} \text { educ }^{1979} \text { afqt }{ }^{1979} \text { family }^{1997} \widehat{\beta}^{*}\right) X_{i}^{\text {age }}{ }^{1979} \text { educ }^{1979} \text { af } q t^{1979} \text { family }^{1997}
\end{aligned}
$$

The standard errors associated with other variables are estimated similarly. 
cohort. Given that workers with higher skills are more likely to receive higher fringe benefits, we expect that skill differences across cohorts increase the unexplained gap in fringe benefit offers across the NLSY97 and NLSY79. We find this is the case for the pooled sample of women, with skill differences explaining $-13 \%$ of the total difference across cohorts for health insurance offers, $-8 \%$ of the total difference across cohorts for life insurance offers and $-12 \%$ of the total difference across cohorts for pension offers. Family background characteristics also worsen for the NLSY97 cohort in comparison to the NLSY79 cohort (at least in terms of changing family structures). Family background characteristics play a more important role in explaining the difference in fringe benefit offers across cohorts for the pooled sample of men than for the pooled sample of women. They explain $12 \%$ of the total difference across cohorts for health insurance offers, $9 \%$ of the total difference across cohorts for life insurance offers and $14 \%$ of the total difference across cohorts for pension offers for the pooled sample of men, but just $6 \%$ of the total difference across cohorts for health insurance offers, $3 \%$ of the total difference across cohorts for life insurance offers and $6 \%$ of the total difference across cohorts for pension offers across cohorts for the pooled sample of women.

Table 5.3 also reports the decomposition results separately for the African American sub-sample. Among African Americans, age is the most important factor explaining the higher fringe benefit offers for the NLSY79 compared to the NLSY97. Age explains $17 \%$ of the total difference across cohorts for health insurance offers, $10 \%$ of the total difference across cohorts for life insurance offers and $30 \%$ of the total difference across cohorts for pension offers for African American men. It explains $21 \%$ of the total difference across cohorts for health insurance offers, $18 \%$ of the total difference across cohorts for life insurance offers and $31 \%$ of the total difference across cohorts for pension offers for African American women. Differences in AFQT scores and years of schooling in explaining the fringe benefit gap across cohorts are important only for African American women, not for African American men. These differences explain $-24 \%$ of the total difference across cohorts for health insurance offers, $-15 \%$ of the total difference across cohorts for life insurance offers and $-13 \%$ of the total difference across cohorts for pension offers for African American women. On the other hand, differences in family background characteristics are important in explaining the gap in fringe benefit offers across cohorts for African American men but not for African American women. Worse family background characteristics of the NLSY97 cohort are associated with lower fringe benefit offers, with a contribution of $9 \%$ of the total difference across cohorts for health insurance offers, $8 \%$ of the total difference across cohorts for life insurance offers and $11 \%$ of the total difference across cohorts for pension offers for African American men.

Table 5.3 gives the decomposition results for the Hispanic sub-sample. Fringe benefit offers are received by more individuals of the NLSY79 cohort than of the NLSY97 cohort. Within the Hispanic sub-sample the most important factor in explaining the higher fringe benefit offer rate of the NLSY79 cohort is the older age profile, with age contributing to $32 \%$ of the total difference across cohorts for health insurance 
offers, $9 \%$ of the total difference across cohorts for life insurance offers and $59 \%$ of the total difference across cohorts for pension offers for Hispanic men. Age explains 35\% of the total difference across cohorts for health insurance offers, $12 \%$ of the total difference across cohorts for life insurance offers and $35 \%$ of the total difference across cohorts for pension offers for Hispanic women. Differences in AFQT scores and years of schooling across cohorts are more important for Hispanic women than for Hispanic men. These differences explain $-24 \%$ of the total difference across cohorts for health insurance offers, $-15 \%$ of the total difference across cohorts for life insurance offers and $-13 \%$ of the total difference across cohorts for pension offers for Hispanic women. We do find that the differences in AFQT scores and years of schooling are important in explaining the higher offer rate of pension plans for Hispanic men in the NLSY79 cohort, explaining $13 \%$ of the total difference across cohorts in pension offers. Differences in family backgrounds across cohorts do not seem to play a very important role for the Hispanic sub-sample, except in explaining $8 \%$ of the higher offer of life insurance for Hispanic men.

For the non-Hispanic white sub-sample, we find the older age profile of the NLSY79 is the most important factor explaining the higher fringe benefit offers for this cohort. Age explains $23 \%$ of the total difference across cohorts for health insurance offers, $15 \%$ of the total difference across cohorts for life insurance offers and $62 \%$ of the total difference across cohorts for pension offers for non-Hispanic white men. It explains $17 \%$ of the total difference across cohorts for offers of health insurance, $14 \%$ of the total difference across cohorts for offers of life insurance and $62 \%$ of the total difference across cohorts for offers of pension. Differences in AFQT scores and years of schooling across cohorts are more important for non-Hispanic white women than for non-Hispanic white men. While skill differences explain $-13 \%$ of the total difference across cohorts for health insurance offers, $-6 \%$ of the total difference across cohorts for life insurance offers and $-9 \%$ of the total difference across cohorts for pensions for non-Hispanic white women, they explain just $2 \%$ of the total difference across cohorts for life insurance offers and $10 \%$ of the total difference across cohorts for pensions for non-Hispanic white men.

In general, we find that a significant part of the different in fringe benefit offers across cohorts can be explained simply by the older age profile of the NLSY79 cohort. As the NLSY97 cohort becomes older and gains labor market experience, the difference from the NLSY79 cohort in terms of fringe benefit offers will become smaller. The changing skills of the NLSY97 cohort compared to the NLSY79 cohort play an important role for women. Instead of explaining the low offer rates of the NLSY97 cohort compared to the NLSY79 cohort, the high skills of women in NLSY97 compared to NLSY79 would have predicted higher offer rates of the NLSY97 cohort so skill differences increase the unexplained gap in fringe benefit offers across cohorts. Note that the overall unexplained gap in fringe benefits remains quite large, particularly for women. For men, the unexplained gap in fringe benefit offers is smaller particularly in case of pension offers. While age, family background, AFQT scores and education differences play a role in explaining the 
low fringe benefits offered to NLSY97 cohort compared to NLSY79 cohort, they collectively fall short of explaining the entire difference, particularly for women.

\section{Conclusion}

Using data from the NLSY79, we find that non-Hispanic whites working full-time in the private sector have significantly higher offers of fringe benefits- health insurance, life insurance and pensions, than do African Americans. This is the case when we compare non-Hispanic whites with African Americans of the same age, and also when we control for individual differences in cognitive ability, years of schooling and family background. This indicates a real disadvantage faced by African Americans in the quality of jobs that they work in. We find that the inequality in fringe benefit offers across non-Hispanic whites and African Americans is larger for men than for women. We find that workers who are older are more likely to be offered fringe benefits as are workers with higher cognitive ability and years of schooling. We find that Hispanics are less likely to be offered fringe benefits than non-Hispanic whites of the same age. However we do not find that Hispanics face a significant disadvantage compared to non-Hispanic whites once we control for cognitive ability, years of schooling and family background.

When we examine data from the NLSY97, we find that non-Hispanic whites working full-time in the private sector are more likely to receive fringe benefit offers than African Americans and Hispanics of similar age. However, the disadvantage disappears when we control for individual differences in cognitive ability, years of schooling and family background.

We also find that offer rates of fringe benefits are far lower in the NLSY97 than the NLSY79. While a large part of the difference can be explained by the older age profile of the NLSY79, a substantial difference remains unexplained. An important question for future research is to explain these low offer rates.

Our work also suggests a number of ideas to explore for future research. Given the nature of the longitudinal data that we use, one can further investigate the impact of inequalities on long-term health well-being of individuals as well as their family members. By making use of firm level data, one can further investigate characteristics of fringe benefits that influence take-up behavior of employees. By understanding the role of fringe benefits in total compensation across racial and ethnic groups one will better measure the extent of inequality in well-being across these groups. 


\section{References}

[1] Altonji, Joseph G., Prashant Bharadwaj and Fabian Lange (2008), 'Changes in the Characteristics of American Youth: Implications for Adult Outcomes,' forthcoming Journal of Labor Economics.

[2] Artz, Benjamin (2010), 'Fringe benefits and job satisfaction,' International Journal of Manpower, Vol. 31 Iss: 6 , pp.626 - 644 .

[3] Chung, W. (2003), 'Fringe Benefits and Inequality in the Labor Market,' Economic Inquiry, 41: 517529.

[4] Fairlie, Robert (2005), 'An Extension of the Blinder-Oaxaca Decomposition Technique to Logit and Probit Models,' Journal of Economics and Social Measurement, 30(4): 305-316.

[5] Fryer, Roland (2010), 'Racial Inequality in the 21st Century: The Declining Significance of Discrimination,' forthcoming in the Handbook of Labor Economics, Vol 4.

[6] Hamermesh, Daniel S. (1999) 'Changing Inequality In Markets For Workplace Amenities,' The Quarterly Journal of Economics, MIT Press, vol. 114(4), pages 1085-1123.

[7] Hersch, Joni and Shelley White-Means (1993), 'Employer-Sponsored Health and Pension Benefits and the Gender/Race Wage Gap,' Social Science Quarterly, Volume 74, Number 4.

[8] Kaiser Family Foundation. 2009. 'Health care Costs, A Primer.' The Henry J. Kaiser Family Foundation, Menlo Park, CA.

[9] Kaiser Family Foundation and Health Research and Educational Trust. 2008. 'Employer Health Benefits - 2008 Annual Survey.' The Henry J. Kaiser Family Foundation, Menlo Park, CA.

[10] Lang, Kevin and Michael Manove. 2011. 'Education and Labor Market Discrimination,' forthcoming American Economic Review.

[11] Levy, Helen (2006), 'Health Insurance and the Wage Gap,' NBER Working Paper 11975.

[12] Mok, Wallace and Zahra Siddique (2009) 'Racial Differences in Fringe Benefits and Compensation,' IZA DP 4435.

[13] Neal, Derek and William Johnson (1996) 'The Role of Pre-Market Factors in Black-White Wage Differences,' Journal of Political Economy, 104(5): 869-895.

[14] Neal, Derek (2004) 'The Measured Black-White Wage Gap among Women Is Too Small,' Journal of Political Economy, University of Chicago Press, vol. 112(S1), pages S1-S28, February. 
[15] Neal, Derek (2006) 'Why has black-white skill convergence stopped?' The Handbook of Economics of Education, vol. 1, ed. E. Hanushek and F. Welch. Amsterdam: North-Holland.

[16] Oaxaca, Ronald,'Male-Female Wage Differentials in Urban Labor Markets,' International Economic Review 14: 693-709.

[17] Rosen, Sherwin (1986), 'The theory of equalizing differences.' Ch. 12 of Orley Ashenfelter and David Card, eds., The Handbook of Labor Economics, vol. 1, pp. 641-92. Elsevier Publishers.

[18] Solberg, Eric and Teresa Laughlin (1995), 'The Gender Pay Gap, Fringe Benefits, and Occupational Crowding,' Industrial and Labor Relations Review, 48(4): 692-708.

[19] U.S. Department of Labor. Various Years. 'Employer Costs for Employee Compensation - March.'

[20] Woodbury, Simon (1983), 'Substitution Between Wage and Non-Wage Benefits,' American Economic Review, Vol. 73, No. 1 (Mar., 1983), pp. 166-182. 





Figure 4.1: Fringe benefit offers by age across race, ethnicity and gender, NLSY79

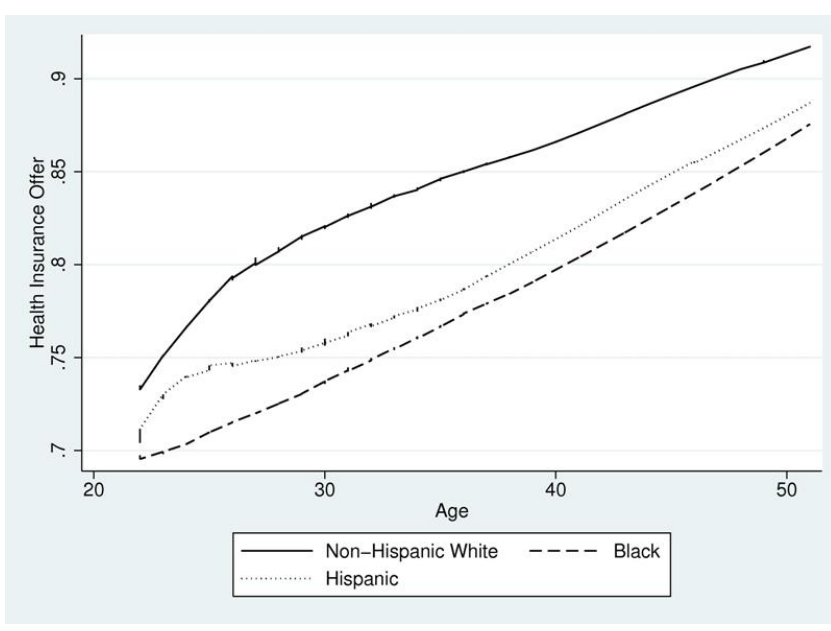

(a) Health Insurance, Male Sample

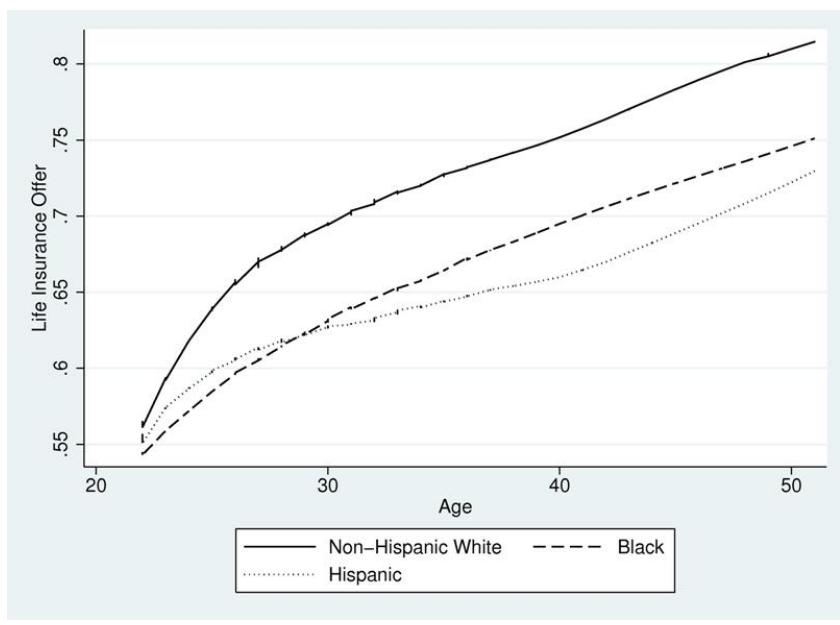

(c) Life Insurance, Male Sample

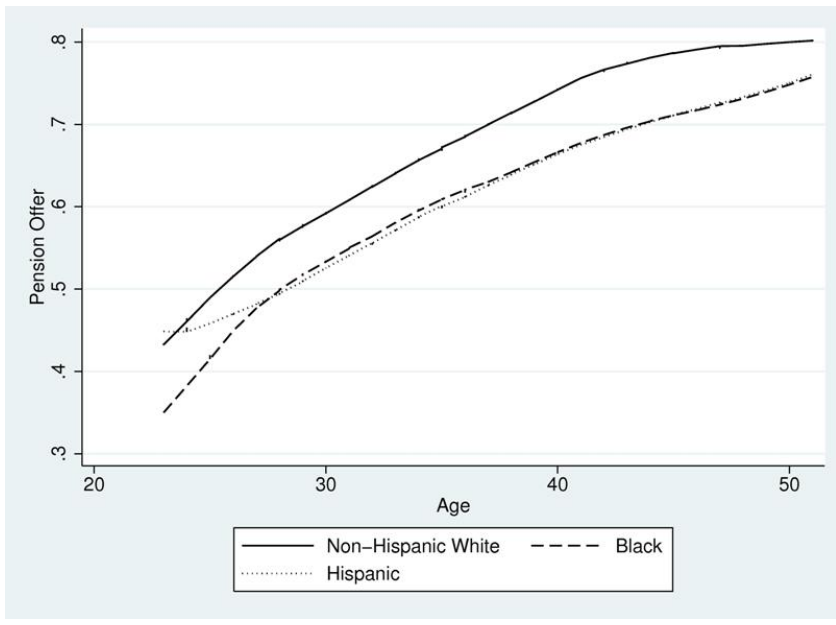

(e) Pension, Male Sample

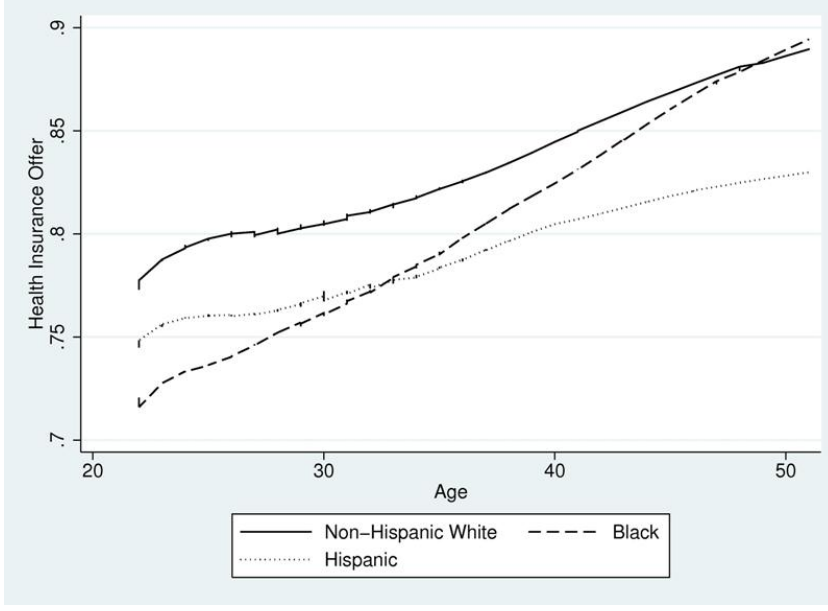

(b) Health Insurance, Female Sample

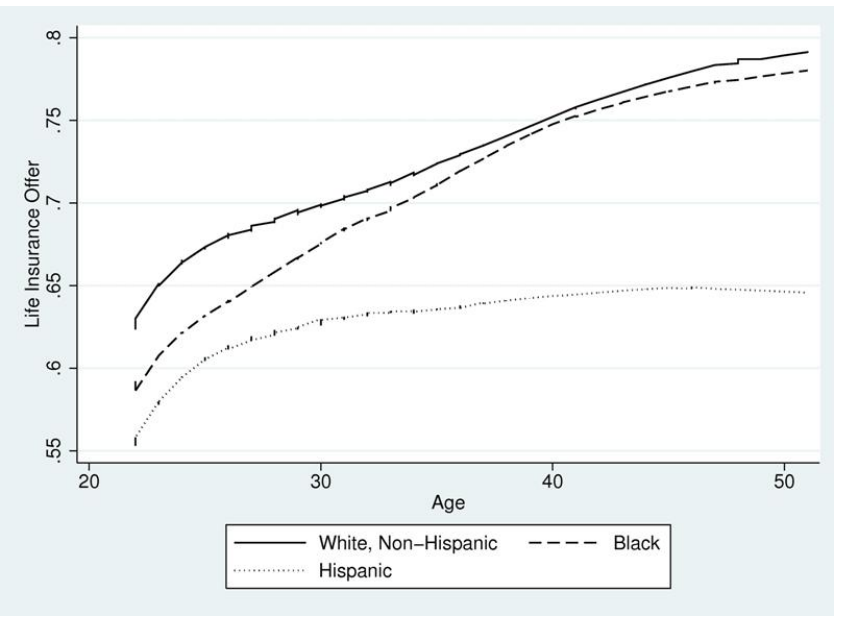

(d) Life Insurance, Female Sample

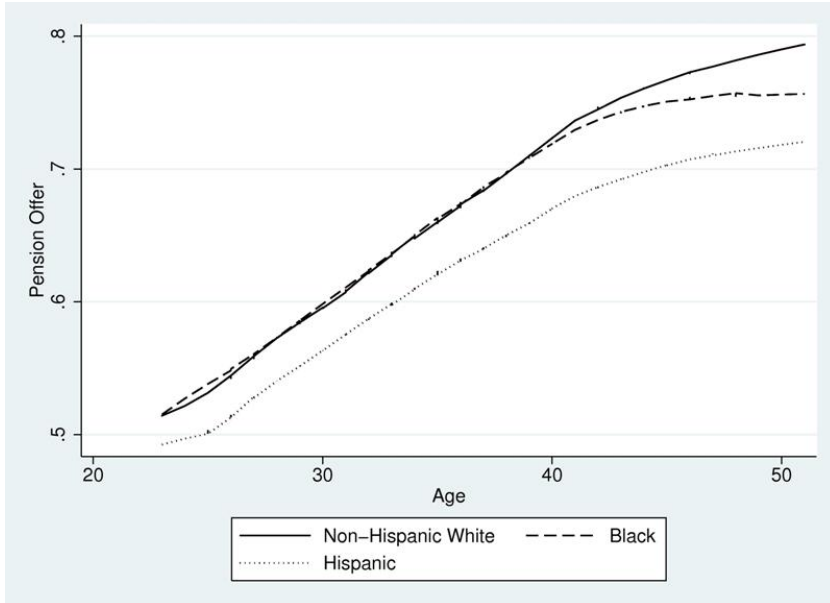

(f) Pension, Female Sample

Notes: Pooled data from 1979-2008 cross-sections of the NLSY79 where the age of the workers is equal to or greater than 22; effectively, this means we drop most observations from the early cross-sections since the NLSY79 cohort was between the ages of 14 and 22 in 1979. We further restrict to full-time workers (working more than 35 hours per week) in the private sector. Locally weighted regressions are estimated on whether a particular fringe benefit is offered by the employer. Questions on pension offers are available only from 1988 onwards. 
Figure 4.2: Fringe benefit offers by age across race, ethnicity and gender, NLSY97

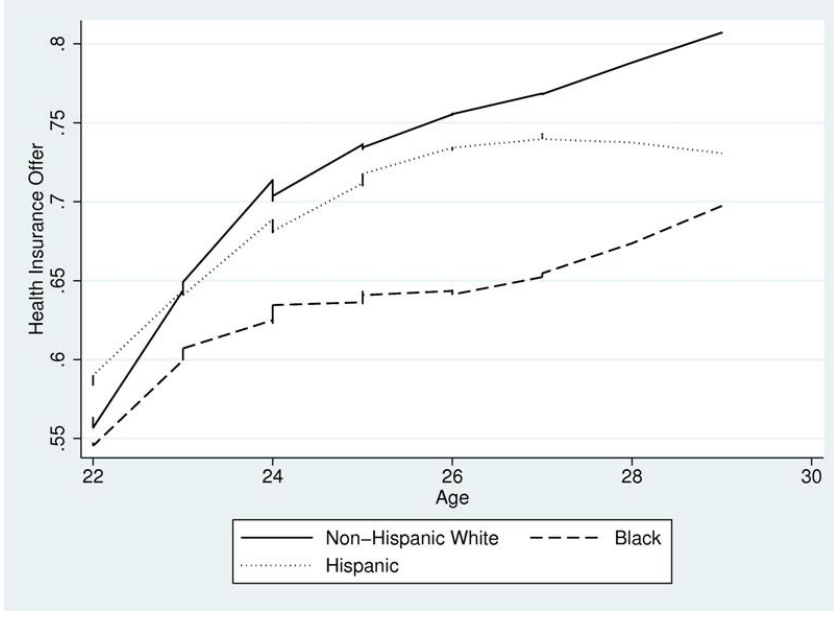

(a) Health Insurance, Male Sample

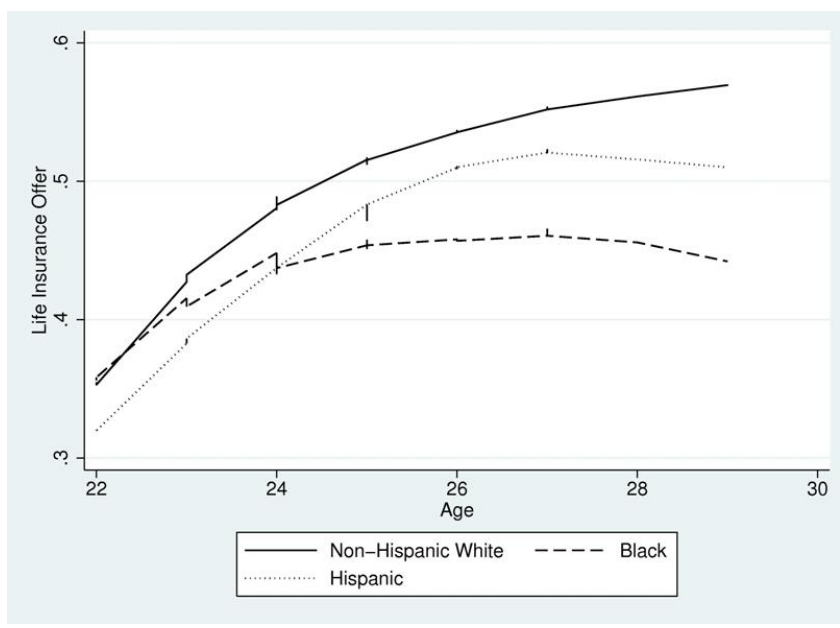

(c) Life Insurance, Male Sample

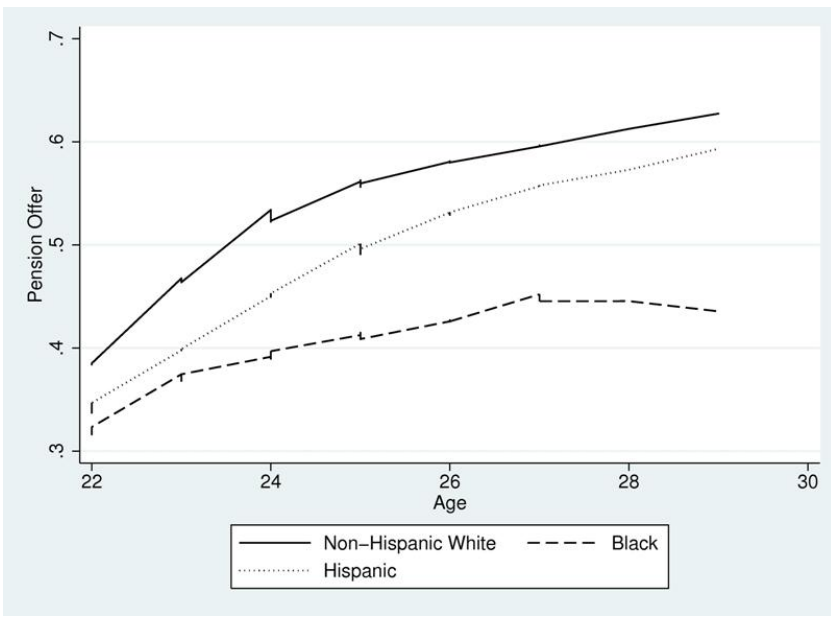

(e) Pension, Male Sample

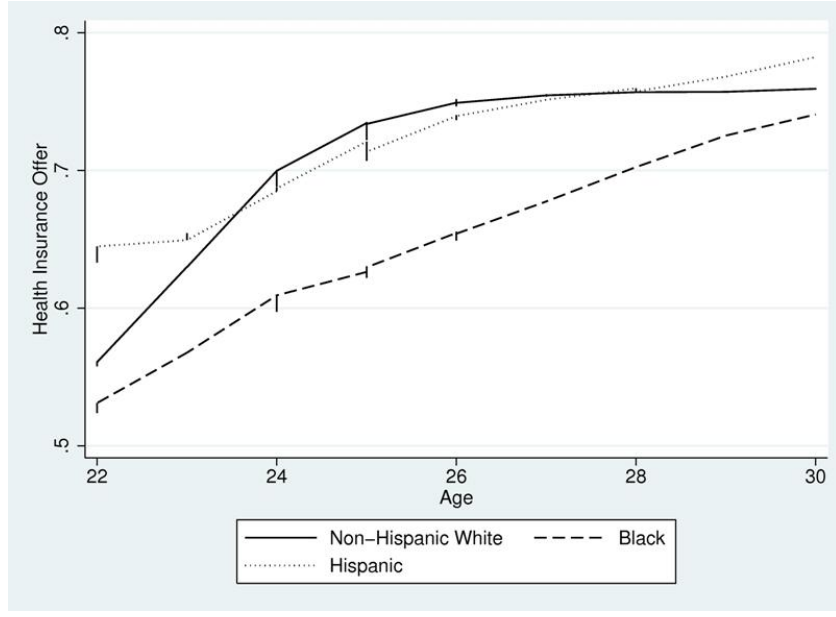

(b) Health Insurance, Female Sample

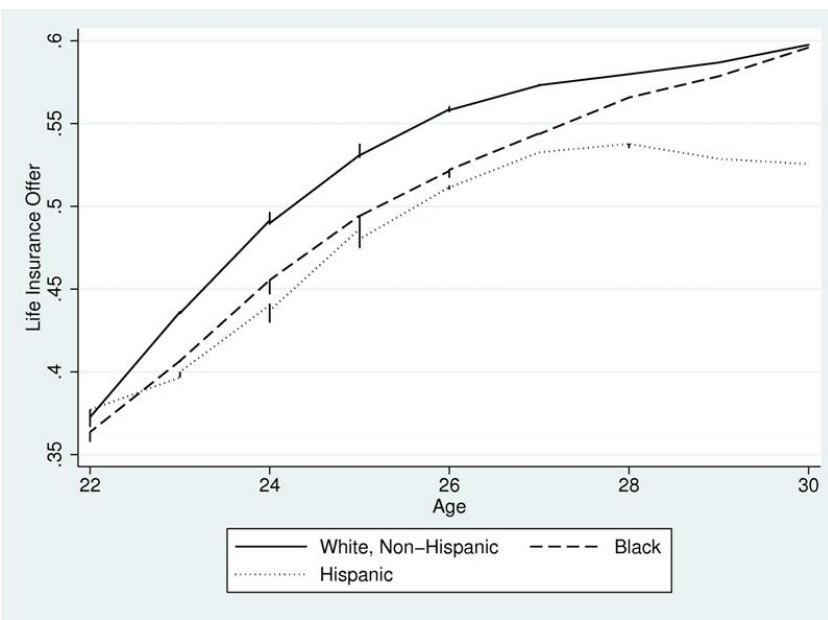

(d) Life Insurance, Female Sample

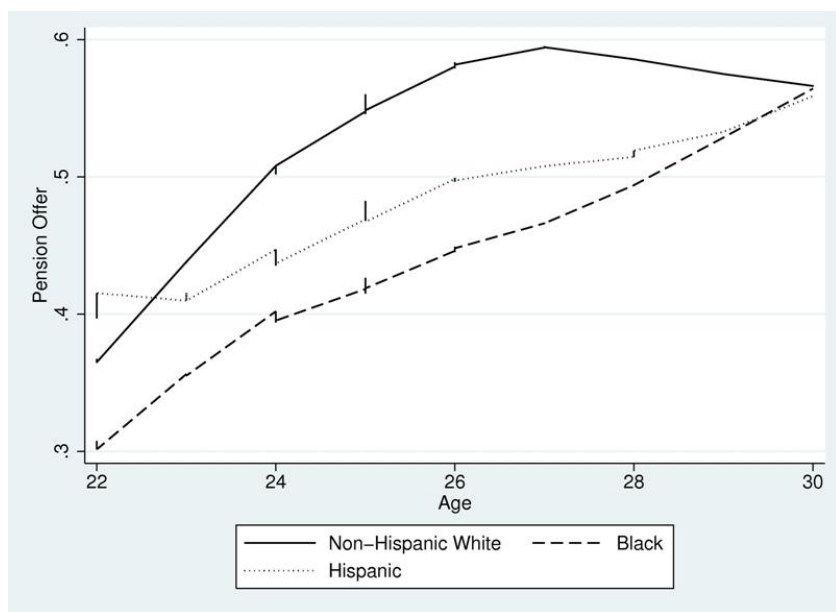

(f) Pension, Female Sample

Notes: Pooled data from the 1997-2009 cross-sections of the NLSY97 where the age of the workers is equal to or greater than 22; effectively, this means we drop observations from the early cross-sections since the NLSY97 cohort was between the ages of 12 and 16 in 1997, so we are left with observations from the 2001-2009 cross-sections. We further restrict to full-time workers (working more than 35 hours per week) in the private sector. Locally weighted regressions are estimated on whether a particular fringe benefit is offered by the employer. 
Figure 5.1.1: Distribution of skills across race, ethnicity and gender, NLSY79

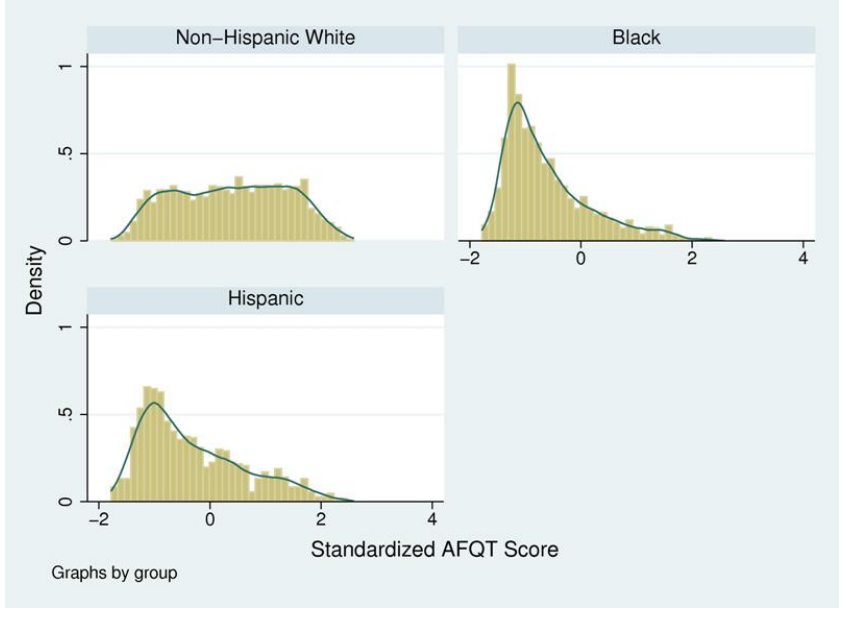

(a) Standardized AFQT scores, Male Sample

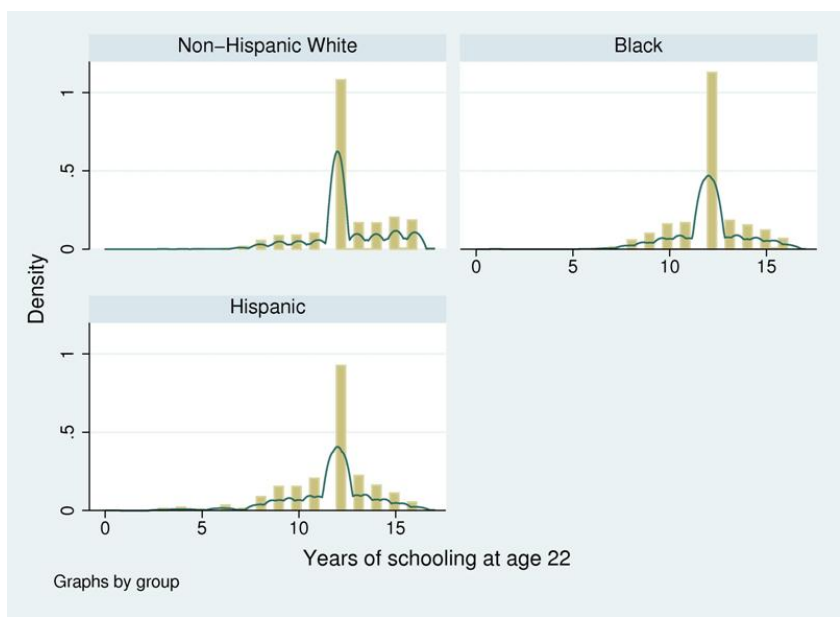

(c) Years of schooling at age 22, Male Sample

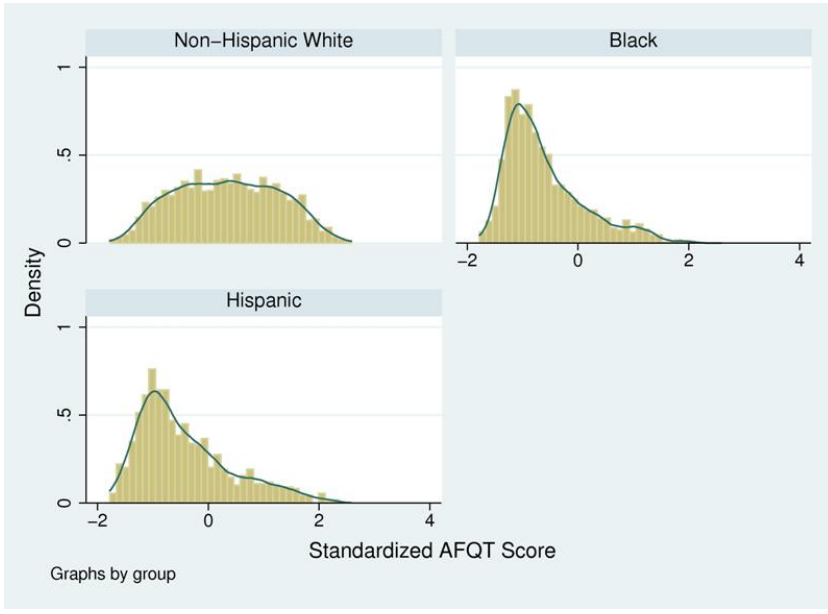

(b) Standardized AFQT scores, Female Sample

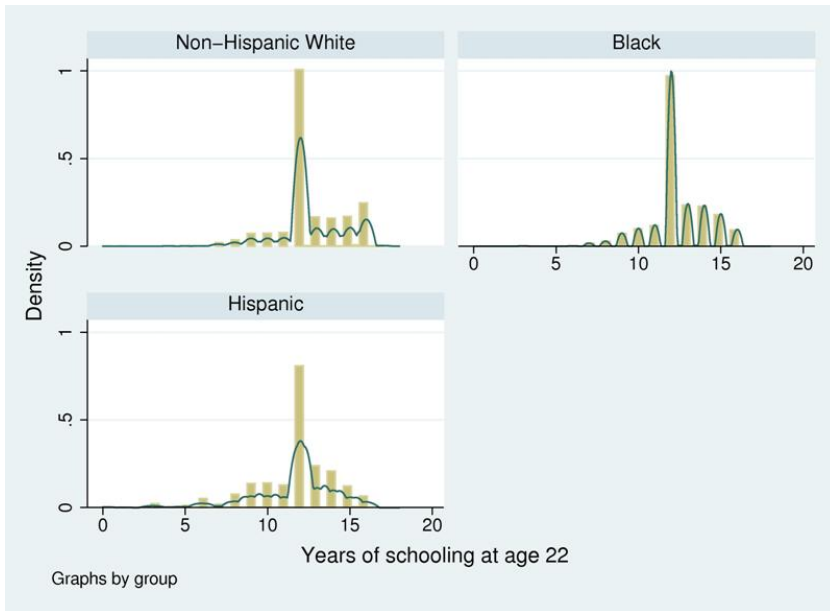

(d) Years of schooling at age 22, Female Sample

Notes: AFQT scores are standardized by age. Distribution refers to the distribution of skills (standardized AFQT scores and years of schooling at age 22) for the complete cross-section of the NLSY79 for which these measures are available. Kernel density estimates overlaid on the histograms. 
Figure 5.1.2: Distribution of skills across race, ethnicity and gender, NLSY97

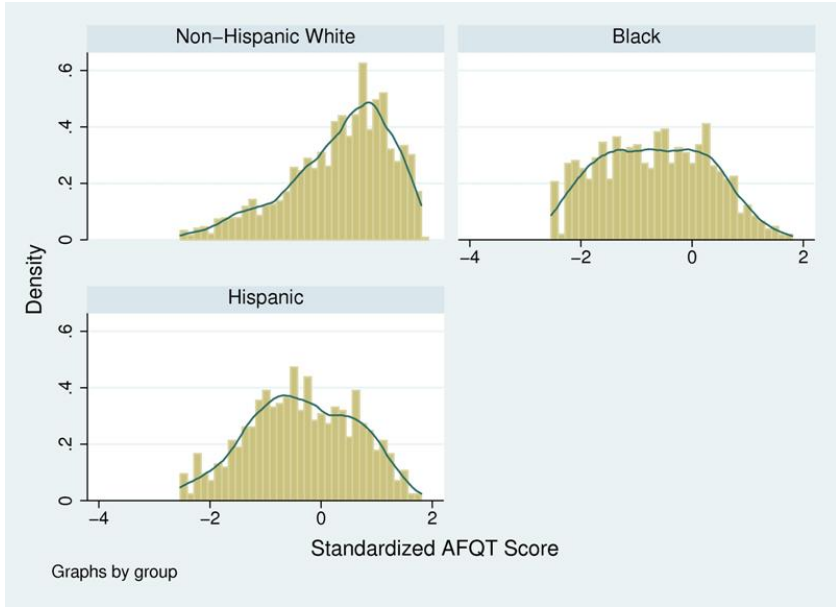

(a) Standardized AFQT scores, Male Sample

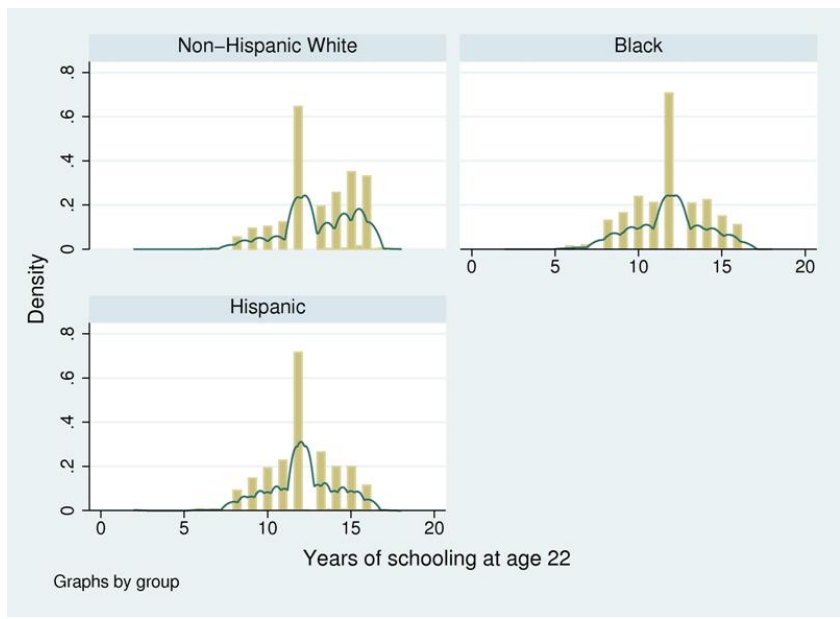

(c) Years of schooling at age 22, Male Sample

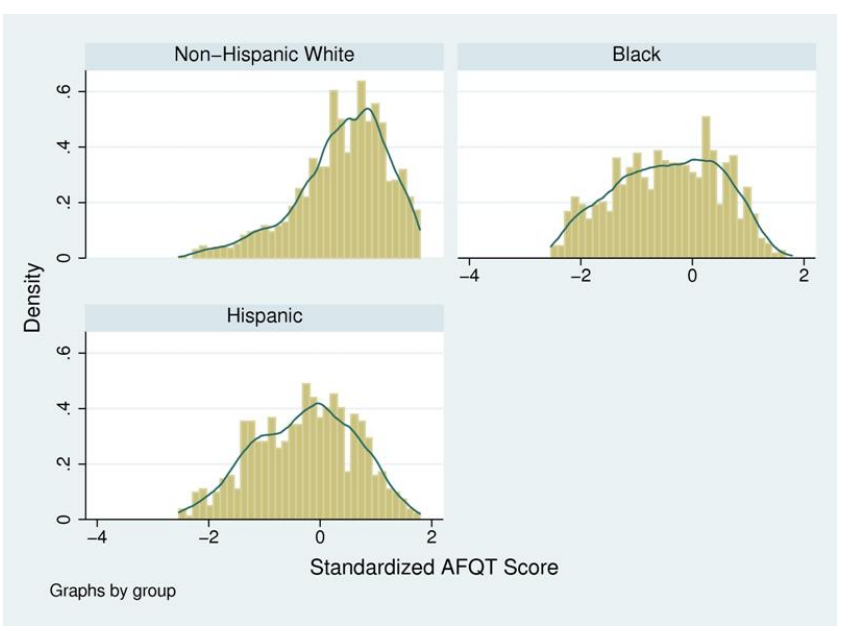

(b) Standardized AFQT scores, Female Sample

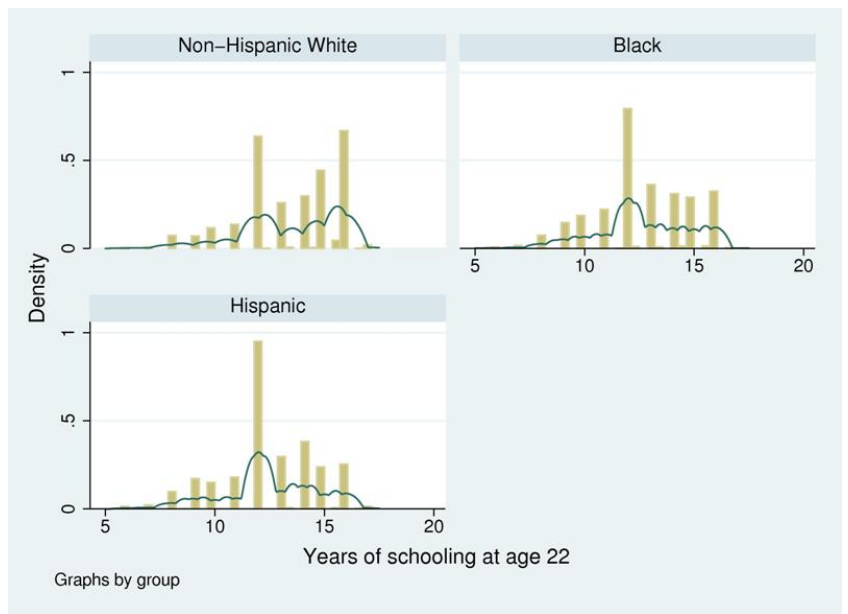

(d) Years of schooling at age 22, Female Sample

Notes: AFQT scores are standardized by age. Distribution refers to the distribution of skills (standardized AFQT scores and years of schooling at age 22) for the complete cross-section of the NLSY97 for which these measures are available. Kernel density estimates overlaid on the histograms. 
Table 5.1: Racial and ethnic gaps in fringe benefit offers, NLSY79

\begin{tabular}{|c|c|c|c|c|c|c|}
\hline \multirow[t]{2}{*}{$\mathbf{X}$} & \multicolumn{3}{|c|}{ Men } & \multicolumn{3}{|c|}{ Women } \\
\hline & $\frac{\partial H}{\partial X}$ & $\frac{\partial L}{\partial X}$ & $\frac{\partial P}{\partial X}$ & $\frac{\partial H}{\partial X}$ & $\frac{\partial L}{\partial X}$ & $\frac{\partial P}{\partial X}$ \\
\hline \multirow[t]{2}{*}{ Black } & $-0.401^{* * *}$ & $-0.472^{* * *}$ & $-0.311^{* * *}$ & $-0.403^{* * *}$ & $-0.408^{* * *}$ & $-0.233^{*}$ \\
\hline & $(0.091)$ & $(0.083)$ & $(0.091)$ & $(0.105)$ & $(0.102)$ & $(0.107)$ \\
\hline \multirow[t]{2}{*}{ Hispanic } & -0.030 & 0.081 & 0.100 & -0.143 & -0.040 & $-0.240^{*}$ \\
\hline & $(0.072)$ & $(0.074)$ & $(0.081)$ & $(0.103)$ & $(0.102)$ & $(0.111)$ \\
\hline \multirow[t]{2}{*}{ Age $\times$ Black } & $0.007^{* * *}$ & $0.008^{* * *}$ & $0.014^{* * *}$ & $0.009^{* * *}$ & $0.009^{* * *}$ & $0.014^{* * *}$ \\
\hline & $(0.001)$ & $(0.001)$ & $(0.001)$ & $(0.001)$ & $(0.001)$ & $(0.001)$ \\
\hline \multirow[t]{2}{*}{ Age $\times$ Hispanic } & $0.007^{* * *}$ & $0.005^{* * *}$ & $0.014^{* * *}$ & $0.007^{* * *}$ & $0.005^{* * *}$ & $0.014^{* * *}$ \\
\hline & $(0.001)$ & $(0.001)$ & $(0.001)$ & $(0.001)$ & $(0.001)$ & $(0.001)$ \\
\hline \multirow[t]{2}{*}{ Age $\times$ Non-Hispanic White } & $0.006^{* * *}$ & $0.006^{* * *}$ & $0.015^{* * *}$ & $0.005^{* * *}$ & $0.006^{* * *}$ & $0.013^{* * *}$ \\
\hline & $(0.001)$ & $(0.001)$ & $(0.001)$ & $(0.001)$ & $(0.001)$ & $(0.001)$ \\
\hline \multirow[t]{2}{*}{ Schooling $\times$ Black } & $0.039^{* * *}$ & $0.055^{* * *}$ & $0.062^{* * *}$ & $0.038^{* * *}$ & $0.049^{* * *}$ & $0.042^{* * *}$ \\
\hline & $(0.004)$ & $(0.005)$ & $(0.005)$ & $(0.004)$ & $(0.005)$ & $(0.006)$ \\
\hline \multirow[t]{2}{*}{ Schooling $\times$ Hispanic } & $0.020^{* * *}$ & $0.024^{* * *}$ & $0.029^{* * *}$ & $0.026^{* * *}$ & $0.030^{* * *}$ & $0.038^{* * *}$ \\
\hline & $(0.004)$ & $(0.004)$ & $(0.005)$ & $(0.004)$ & $(0.005)$ & $(0.005)$ \\
\hline \multirow[t]{2}{*}{ Schooling $\times$ Non-Hispanic White } & $0.030^{* * *}$ & $0.034^{* * *}$ & $0.045^{* * *}$ & $0.019^{* * *}$ & $0.025^{* * *}$ & $0.023^{* * *}$ \\
\hline & $(0.002)$ & $(0.003)$ & $(0.003)$ & $(0.003)$ & $(0.004)$ & $(0.004)$ \\
\hline \multirow[t]{2}{*}{$A F Q T \times$ Black } & $0.036^{* * *}$ & $0.056^{* * *}$ & $0.044^{* * *}$ & $0.065^{* * *}$ & $0.068^{* * *}$ & $0.059^{* * *}$ \\
\hline & $(0.009)$ & $(0.011)$ & $(0.011)$ & $(0.012)$ & $(0.013)$ & $(0.013)$ \\
\hline \multirow{2}{*}{$A F Q T \times$ Hispanic } & $0.041^{* * *}$ & $0.062^{* * *}$ & $0.047^{* * *}$ & $0.075^{* * *}$ & $0.099^{* * *}$ & $0.048^{* * *}$ \\
\hline & $(0.009)$ & $(0.011)$ & $(0.012)$ & $(0.012)$ & $(0.014)$ & $(0.015)$ \\
\hline \multirow[t]{2}{*}{$A F Q T \times$ Non-Hispanic White } & $0.053^{* * *}$ & $0.076^{* * *}$ & $0.071^{* * *}$ & $0.058^{* * *}$ & $0.057^{* * *}$ & $0.088^{* * *}$ \\
\hline & $(0.005)$ & $(0.007)$ & $(0.007)$ & $(0.007)$ & $(0.008)$ & $(0.008)$ \\
\hline \multirow[t]{2}{*}{$A F Q T^{2} \times$ Black } & 0.000 & -0.008 & -0.012 & $-0.023^{* *}$ & $-0.038^{* * *}$ & $-0.071^{* * *}$ \\
\hline & $(0.007)$ & $(0.009)$ & $(0.009)$ & $(0.010)$ & $(0.012)$ & $(0.011)$ \\
\hline \multirow[t]{2}{*}{$A F Q T^{2} \times$ Hispanic } & -0.004 & $-0.022^{* * *}$ & $-0.026^{* * *}$ & $-0.033^{* * *}$ & $-0.039^{* * *}$ & $-0.046^{* * *}$ \\
\hline & $(0.007)$ & $(0.008)$ & $(0.009)$ & $(0.010)$ & $(0.012)$ & $(0.012)$ \\
\hline \multirow{2}{*}{$A F Q T^{2} \times$ Non-Hispanic White } & $-0.014^{* * *}$ & $-0.017^{* * *}$ & $-0.016^{* * *}$ & -0.008 & 0.001 & $-0.018^{* *}$ \\
\hline & $(0.004)$ & $(0.004)$ & $(0.004)$ & $(0.005)$ & $(0.006)$ & $(0.006)$ \\
\hline \multirow[t]{2}{*}{ Fathers Schooling $\times$ Black } & -0.001 & -0.002 & 0.001 & $0.005^{* * *}$ & $0.007^{* * *}$ & $0.008^{* * *}$ \\
\hline & $(0.002)$ & $(0.002)$ & $(0.002)$ & $(0.002)$ & $(0.002)$ & $(0.003)$ \\
\hline \multirow[t]{2}{*}{ Fathers Schooling $\times$ Hispanic } & 0.000 & -0.002 & 0.003 & 0.004 & $0.005^{* *}$ & $0.008^{* * *}$ \\
\hline & $(0.002)$ & $(0.002)$ & $(0.002)$ & $(0.002)$ & $(0.003)$ & $(0.003)$ \\
\hline \multirow[t]{2}{*}{ Fathers Schooling $\times$ Non-Hispanic White } & -0.002 & -0.002 & -0.004 & -0.001 & 0.000 & 0.000 \\
\hline & $(0.001)$ & $(0.002)$ & $(0.002)$ & $(0.002)$ & $(0.002)$ & $(0.002)$ \\
\hline \multirow[t]{2}{*}{ Mothers Schooling $\times$ Black } & $0.005^{*}$ & 0.006 & 0.005 & -0.004 & -0.003 & -0.001 \\
\hline & $(0.002)$ & $(0.003)$ & $(0.003)$ & $(0.003)$ & $(0.003)$ & $(0.003)$ \\
\hline Mothers Schooling $\times$ Hispanic & -0.001 & -0.002 & 0.001 & 0.000 & -0.002 & 0.002 \\
\hline & $(0.002)$ & $(0.002)$ & $(0.002)$ & $(0.003)$ & $(0.003)$ & $(0.003)$ \\
\hline Mothers Schooling $\times$ Non-Hispanic White & $-0.005^{* * *}$ & $-0.007^{* * *}$ & $-0.006^{* * *}$ & -0.002 & -0.004 & -0.003 \\
\hline & $(0.002)$ & $(0.002)$ & $(0.002)$ & $(0.002)$ & $(0.002)$ & $(0.003)$ \\
\hline Living with Parents $\times$ Black & $0.035^{* * *}$ & $0.034^{* * *}$ & $0.029^{*}$ & 0.009 & $0.035^{* *}$ & 0.010 \\
\hline & $(0.010)$ & $(0.013)$ & $(0.014)$ & $(0.012)$ & $(0.014)$ & $(0.015)$ \\
\hline Living with Parents $\times$ Hispanic & $0.042^{* * *}$ & $0.033^{*}$ & $0.037^{*}$ & 0.005 & 0.016 & 0.024 \\
\hline & $(0.012)$ & $(0.016)$ & $(0.018)$ & $(0.017)$ & $(0.020)$ & $(0.021)$ \\
\hline Living with Parents $\times$ Non-Hispanic White & $0.035^{* * *}$ & $0.058^{* * *}$ & $0.074^{* * *}$ & $0.052^{* * *}$ & $0.044^{* * *}$ & $0.061^{* * *}$ \\
\hline & $(0.008)$ & $(0.010)$ & $(0.011)$ & $(0.009)$ & $(0.012)$ & $(0.012)$ \\
\hline $\mathbf{N}$ & 23,352 & 23,052 & 23,390 & 17,410 & 17,261 & 17,441 \\
\hline
\end{tabular}

${ }^{1}$ All cross-sections of the NLSY79 from 1979 to 2008 are pooled together. Only observations where the individual is twenty two years old or more, is working full-time (more than thirty five hours per week) in the private sector and for whom non-missing fringe benefit offers, skill measures and background characteristics exist are retained for estimation. Each column gives the racial and ethnic gap in the given fringe benefit offer for the specific sub-sample (male or female) when the full set of skill and background controls are added to a probit specification. Standard errors are given in parentheses. 
Table 5.2: Racial and ethnic gaps in fringe benefit offers, NLSY97

\begin{tabular}{|c|c|c|c|c|c|c|}
\hline \multirow[t]{2}{*}{$\mathbf{X}$} & \multicolumn{3}{|c|}{ Men } & \multicolumn{3}{|c|}{ Women } \\
\hline & $\frac{\partial H}{\partial X}$ & $\frac{\partial L}{\partial X}$ & $\frac{\partial P}{\partial X}$ & $\frac{\partial H}{\partial X}$ & $\frac{\partial L}{\partial X}$ & $\frac{\partial P}{\partial X}$ \\
\hline \multirow[t]{2}{*}{ Black } & 0.152 & 0.345 & -0.103 & -0.253 & -0.060 & -0.236 \\
\hline & $(0.193)$ & $(0.219)$ & $(0.265)$ & $(0.271)$ & $(0.271)$ & $(0.249)$ \\
\hline \multirow[t]{2}{*}{ Hispanic } & -0.023 & -0.088 & -0.217 & 0.268 & -0.144 & 0.335 \\
\hline & $(0.230)$ & $(0.239)$ & $(0.227)$ & $(0.161)$ & $(0.262)$ & $(0.229)$ \\
\hline \multirow[t]{2}{*}{ Age $\times$ Black } & $0.016^{*}$ & 0.014 & $0.020^{* *}$ & $0.026^{* * *}$ & $0.036^{* * *}$ & $0.031^{* * *}$ \\
\hline & $(0.007)$ & $(0.008)$ & $(0.008)$ & $(0.007)$ & $(0.008)$ & $(0.008)$ \\
\hline \multirow[t]{2}{*}{ Age $\times$ Hispanic } & $0.027^{* * *}$ & $0.036^{* * *}$ & $0.043^{* * *}$ & $0.026^{* * *}$ & $0.033^{* * *}$ & $0.026^{* * *}$ \\
\hline & $(0.007)$ & $(0.007)$ & $(0.007)$ & $(0.008)$ & $(0.008)$ & $(0.008)$ \\
\hline \multirow{2}{*}{ Age $\times$ Non-Hispanic White } & $0.036^{* * *}$ & $0.032^{* * *}$ & $0.035^{* * *}$ & $0.034^{* * *}$ & $0.035^{* * *}$ & $0.039^{* * *}$ \\
\hline & $(0.004)$ & $(0.004)$ & $(0.004)$ & $(0.004)$ & $(0.005)$ & $(0.005)$ \\
\hline \multirow[t]{2}{*}{ Schooling $\times$ Black } & $0.031^{* * *}$ & $0.028^{* * *}$ & $0.049^{* * *}$ & 0.016 & 0.017 & $0.046^{* * *}$ \\
\hline & $(0.008)$ & $(0.009)$ & $(0.010)$ & $(0.009)$ & $(0.010)$ & $(0.010)$ \\
\hline \multirow[t]{2}{*}{ Schooling $\times$ Hispanic } & $0.038^{* * *}$ & $0.036^{* * *}$ & $0.045^{* * *}$ & 0.011 & $0.022^{* *}$ & $0.025^{* * *}$ \\
\hline & $(0.008)$ & $(0.009)$ & $(0.009)$ & $(0.009)$ & $(0.009)$ & $(0.009)$ \\
\hline \multirow{2}{*}{ Schooling $\times$ Non-Hispanic White } & $0.026^{* * *}$ & $0.044^{* * *}$ & $0.042^{* * *}$ & $0.012^{* *}$ & $0.019^{* * *}$ & $0.026^{* * *}$ \\
\hline & $(0.005)$ & $(0.005)$ & $(0.005)$ & $(0.005)$ & $(0.005)$ & $(0.005)$ \\
\hline \multirow[t]{2}{*}{$A F Q T \times$ Black } & $0.052^{* *}$ & 0.035 & 0.028 & $0.080^{* * *}$ & $0.127^{* * *}$ & $0.105^{* * *}$ \\
\hline & $(0.023)$ & $(0.024)$ & $(0.025)$ & $(0.023)$ & $(0.024)$ & $(0.024)$ \\
\hline \multirow[t]{2}{*}{$A F Q T \times$ Hispanic } & 0.000 & 0.022 & -0.004 & $0.059^{* * *}$ & $0.069^{* * *}$ & $0.063^{* * *}$ \\
\hline & $(0.019)$ & $(0.020)$ & $(0.021)$ & $(0.021)$ & $(0.022)$ & $(0.022)$ \\
\hline \multirow[t]{2}{*}{$A F Q T \times$ Non-Hispanic White } & $0.034^{* * *}$ & $0.044^{* * *}$ & $0.047^{* * *}$ & $0.084^{* * *}$ & $0.083^{* * *}$ & $0.102^{* * *}$ \\
\hline & $(0.010)$ & $(0.011)$ & $(0.011)$ & $(0.013)$ & $(0.015)$ & $(0.016)$ \\
\hline \multirow{2}{*}{$A F Q T^{2} \times$ Black } & -0.013 & $-0.041^{* * *}$ & $-0.047^{* * *}$ & 0.025 & 0.003 & -0.005 \\
\hline & $(0.013)$ & $(0.015)$ & $(0.016)$ & $(0.015)$ & $(0.017)$ & $(0.018)$ \\
\hline \multirow{2}{*}{$A F Q T^{2} \times$ Hispanic } & -0.012 & -0.021 & $-0.054^{* * *}$ & $-0.037^{* *}$ & -0.007 & $-0.040^{* *}$ \\
\hline & $(0.013)$ & $(0.015)$ & $(0.015)$ & $(0.015)$ & $(0.017)$ & $(0.017)$ \\
\hline \multirow[t]{2}{*}{$A F Q T^{2} \times$ Non-Hispanic White } & -0.002 & $0.015^{*}$ & 0.010 & $-0.023^{*}$ & $-0.030^{* *}$ & $-0.037^{* * *}$ \\
\hline & $(0.007)$ & $(0.008)$ & $(0.008)$ & $(0.011)$ & $(0.012)$ & $(0.012)$ \\
\hline \multirow[t]{2}{*}{ Fathers Schooling $\times$ Black } & 0.000 & -0.004 & 0.005 & -0.008 & $-0.023^{* * *}$ & -0.014 \\
\hline & $(0.003)$ & $(0.004)$ & $(0.003)$ & $(0.007)$ & $(0.008)$ & $(0.008)$ \\
\hline \multirow[t]{2}{*}{ Fathers Schooling $\times$ Hispanic } & 0.000 & -0.007 & -0.001 & 0.003 & 0.001 & 0.003 \\
\hline & $(0.003)$ & $(0.004)$ & $(0.003)$ & $(0.003)$ & $(0.003)$ & $(0.003)$ \\
\hline \multirow[t]{2}{*}{ Fathers Schooling $\times$ Non-Hispanic White } & $-0.008^{* *}$ & $-0.014^{* * *}$ & $-0.007^{*}$ & -0.001 & -0.001 & 0.000 \\
\hline & $(0.003)$ & $(0.004)$ & $(0.004)$ & $(0.004)$ & $(0.004)$ & $(0.004)$ \\
\hline \multirow[t]{2}{*}{ Mothers Schooling $\times$ Black } & 0.007 & 0.008 & 0.009 & $0.028^{* * *}$ & 0.017 & 0.016 \\
\hline & $(0.007)$ & $(0.008)$ & $(0.008)$ & $(0.008)$ & $(0.009)$ & $(0.009)$ \\
\hline Mothers Schooling $\times$ Hispanic & -0.002 & -0.005 & $-0.011^{* *}$ & $-0.013^{* * *}$ & 0.003 & -0.008 \\
\hline & $(0.003)$ & $(0.004)$ & $(0.005)$ & $(0.005)$ & $(0.005)$ & $(0.005)$ \\
\hline Mothers Schooling $\times$ Non-Hispanic White & -0.001 & -0.006 & -0.007 & -0.002 & $-0.010^{* *}$ & -0.005 \\
\hline & $(0.004)$ & $(0.004)$ & $(0.004)$ & $(0.004)$ & $(0.004)$ & $(0.004)$ \\
\hline Living with Parents $\times$ Black & $0.071^{* * *}$ & $0.080^{* * *}$ & 0.059 & $0.062^{* *}$ & 0.046 & 0.044 \\
\hline & $(0.025)$ & $(0.031)$ & $(0.031)$ & $(0.025)$ & $(0.030)$ & $(0.030)$ \\
\hline Living with Parents $\times$ Hispanic & 0.024 & 0.011 & -0.012 & 0.001 & -0.066 & -0.035 \\
\hline & $(0.028)$ & $(0.032)$ & $(0.032)$ & $(0.032)$ & $(0.034)$ & $(0.034)$ \\
\hline Living with Parents $\times$ Non-Hispanic White & -0.013 & -0.014 & 0.004 & -0.026 & -0.030 & -0.022 \\
\hline & $(0.017)$ & $(0.018)$ & $(0.018)$ & $(0.019)$ & $(0.020)$ & $(0.020)$ \\
\hline $\mathbf{N}$ & 6,615 & 6,615 & 6,615 & 5,614 & 5,614 & 5,614 \\
\hline
\end{tabular}

${ }^{1}$ All cross-sections of the NLSY97 from 1997 to 2009 are pooled together. Only observations where the individual is twenty two years old or more, is working full-time (more than thirty five hours per week) in the private sector and for whom non-missing fringe benefit offers, skill measures and background characteristics exist are retained for estimation. Effectively, the sample restrictions mean we drop observations from the early cross-sections since the NLSY97 cohort was between the ages of 12 and 16 in 1997 , so we are left with observations from the 2001-2009 cross-sections. Each column gives the racial and ethnic gap in the given fringe benefit offer for the specific sub-sample (male or female) when the full set of skill and background controls are added to a probit specification. Standard errors are given in parentheses. 
Table 5.3: Gaps in fringe benefit offers across cohorts, NLSY79 and NLSY97

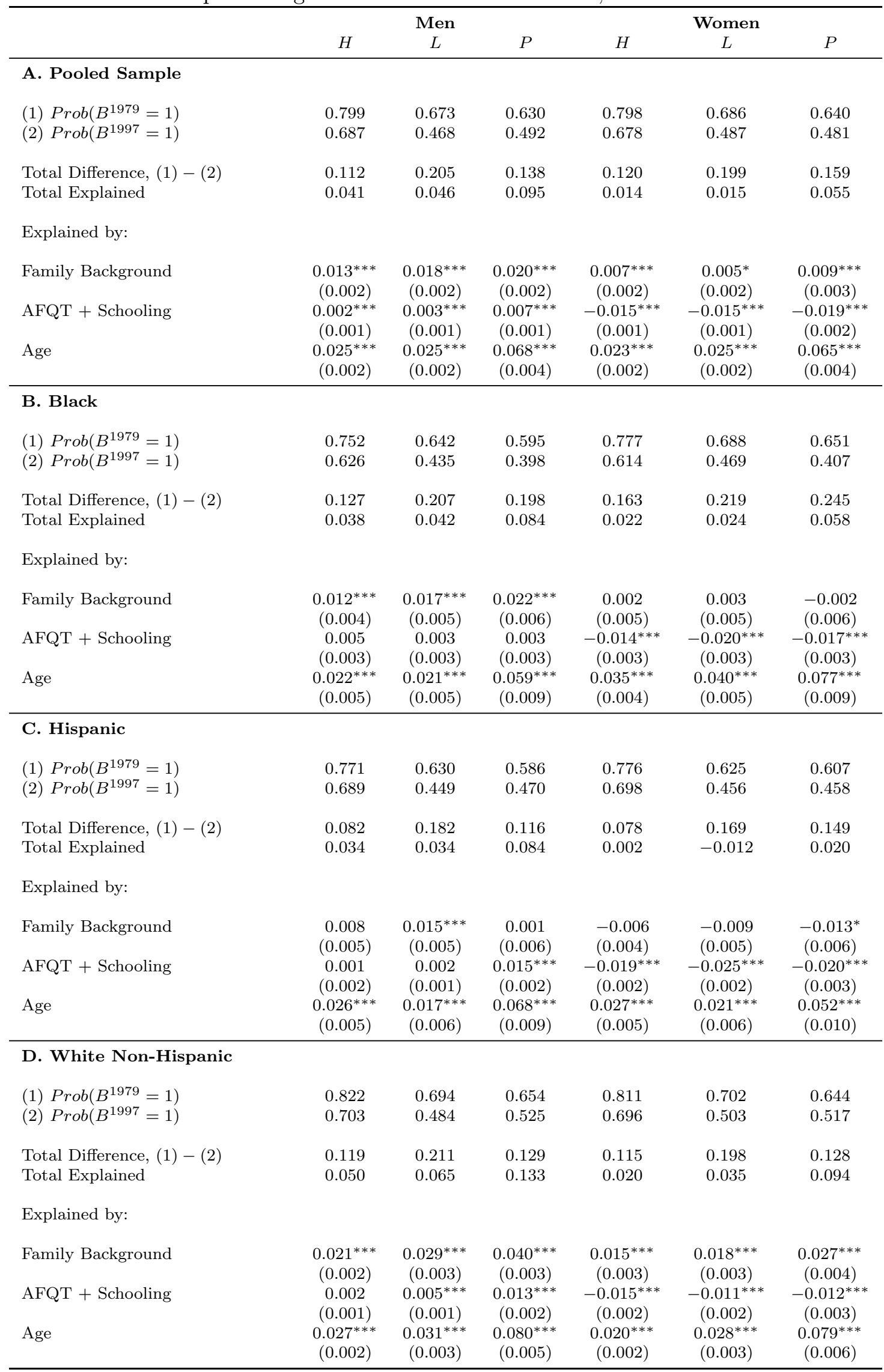

${ }^{1}$ The two groups for the decompositions consist of: 1 . All cross-sections of the NLSY79 (from 1979 to 2008) where the individual is twenty one years old or more, is working full-time (more than thirty five hours per week) in the private sector and for whom non-missing fringe benefit offers, skill measures and background characteristics exist, 2. All cross-sections of the NLSY97 (from 1997 to 2009) where the individual is twenty one years old or more, is working full-time (more than thirty five hours per week) in the private sector and for whom non-missing fringe benefit offers, skill measures and background characteristics exist. 


\section{A Appendix Tables}

Table A.1: Skill and Background Characteristics

\begin{tabular}{|c|c|c|c|c|c|c|}
\hline & \multicolumn{3}{|c|}{ Men } & \multicolumn{3}{|c|}{ Women } \\
\hline & $\begin{array}{l}\text { Non-Hispanic } \\
\text { White }\end{array}$ & Black & Hispanic & $\begin{array}{l}\text { Non-Hispanic } \\
\text { White }\end{array}$ & Black & Hispanic \\
\hline \multicolumn{7}{|l|}{ 1. NLSY79 } \\
\hline Years of schooling at age 22 & $\begin{array}{l}12.60 \\
(1.91)\end{array}$ & $\begin{array}{l}12.24 \\
(1.74)\end{array}$ & $\begin{array}{l}11.90 \\
(2.08)\end{array}$ & $\begin{array}{l}12.78 \\
(1.93)\end{array}$ & $\begin{array}{l}12.62 \\
(1.72)\end{array}$ & $\begin{array}{l}11.95 \\
(1.28)\end{array}$ \\
\hline Standardized AFQT score & $\begin{array}{c}0.45 \\
(0.99)\end{array}$ & $\begin{array}{l}-0.55 \\
(0.78)\end{array}$ & $\begin{array}{l}-0.23 \\
(0.93)\end{array}$ & $\begin{array}{c}0.39 \\
(0.91)\end{array}$ & $\begin{array}{l}-0.56 \\
(0.72)\end{array}$ & $\begin{array}{l}-0.37 \\
(0.86)\end{array}$ \\
\hline \multicolumn{7}{|l|}{ Family Background } \\
\hline Fathers years of schooling & $\begin{array}{l}11.89 \\
(3.47)\end{array}$ & $\begin{array}{l}10.29 \\
(3.32)\end{array}$ & $\begin{array}{l}8.38 \\
(4.81)\end{array}$ & $\begin{array}{l}11.85 \\
(3.41)\end{array}$ & $\begin{array}{l}10.09 \\
(3.56)\end{array}$ & $\begin{array}{l}8.26 \\
(4.64)\end{array}$ \\
\hline Mothers years of schooling & $\begin{array}{l}11.79 \\
(2.52)\end{array}$ & $\begin{array}{l}11.05 \\
(2.49)\end{array}$ & $\begin{array}{l}8.05 \\
(4.38)\end{array}$ & $\begin{array}{l}11.70 \\
(2.55)\end{array}$ & $\begin{array}{l}10.83 \\
(2.74)\end{array}$ & $\begin{array}{l}8.07 \\
(4.02)\end{array}$ \\
\hline $\begin{array}{l}\text { Fraction living with both } \\
\text { biological parents at age } 14\end{array}$ & $\begin{array}{c}0.80 \\
(0.40)\end{array}$ & $\begin{array}{c}0.60 \\
(0.49)\end{array}$ & $\begin{array}{c}0.74 \\
(0.44)\end{array}$ & $\begin{array}{c}0.79 \\
(0.41)\end{array}$ & $\begin{array}{c}0.60 \\
(0.49)\end{array}$ & $\begin{array}{l}0.75 \\
(0.43)\end{array}$ \\
\hline $\mathbf{N}$ & 2,689 & 892 & 576 & 2,732 & 931 & 638 \\
\hline \multicolumn{7}{|l|}{ 2. NLSY97 } \\
\hline Years of schooling at age 22 & $\begin{array}{l}13.22 \\
(2.10)\end{array}$ & $\begin{array}{l}12.20 \\
(2.11)\end{array}$ & $\begin{array}{l}12.40 \\
(1.92)\end{array}$ & $\begin{array}{l}13.67 \\
(2.13)\end{array}$ & $\begin{array}{l}13.05 \\
(2.09)\end{array}$ & $\begin{array}{l}12.89 \\
(1.96)\end{array}$ \\
\hline Standardized AFQT score & $\begin{array}{c}0.39 \\
(0.92)\end{array}$ & $\begin{array}{l}-0.56 \\
(1.01)\end{array}$ & $\begin{array}{l}-0.26 \\
(0.94)\end{array}$ & $\begin{array}{l}0.46 \\
(0.80)\end{array}$ & $\begin{array}{l}-0.31 \\
(0.92)\end{array}$ & $\begin{array}{l}-0.20 \\
(0.91)\end{array}$ \\
\hline \multicolumn{7}{|l|}{ Family Background } \\
\hline Fathers years of schooling & $\begin{array}{l}13.79 \\
(3.55)\end{array}$ & $\begin{array}{l}12.60 \\
(5.86)\end{array}$ & $\begin{array}{l}11.04 \\
(5.49)\end{array}$ & $\begin{array}{l}13.58 \\
(2.80)\end{array}$ & $\begin{array}{l}12.46 \\
(2.17)\end{array}$ & $\begin{array}{l}11.05 \\
(5.58)\end{array}$ \\
\hline Mothers years of schooling & $\begin{array}{l}13.64 \\
(2.53)\end{array}$ & $\begin{array}{l}12.68 \\
(2.17)\end{array}$ & $\begin{array}{l}11.38 \\
(6.61)\end{array}$ & $\begin{array}{l}13.57 \\
(2.51)\end{array}$ & $\begin{array}{l}12.66 \\
(2.07)\end{array}$ & $\begin{array}{l}10.71 \\
(3.71)\end{array}$ \\
\hline $\begin{array}{l}\text { Fraction living with both } \\
\text { biological parents at age } 14\end{array}$ & $\begin{array}{c}0.71 \\
(0.46)\end{array}$ & $\begin{array}{c}0.43 \\
(0.50)\end{array}$ & $\begin{array}{c}0.67 \\
(0.47)\end{array}$ & $\begin{array}{l}0.66 \\
(0.47)\end{array}$ & $\begin{array}{c}0.44 \\
(0.50)\end{array}$ & $\begin{array}{l}0.68 \\
(0.47)\end{array}$ \\
\hline $\mathbf{N}$ & 1,486 & 476 & 445 & 1,412 & 562 & 423 \\
\hline
\end{tabular}

${ }^{1}$ Skill measures and background characteristics for the NLSY79 and NLSY97 cross-section with non-missing skill measures and background characteristics. Standard errors are given in parentheses. 


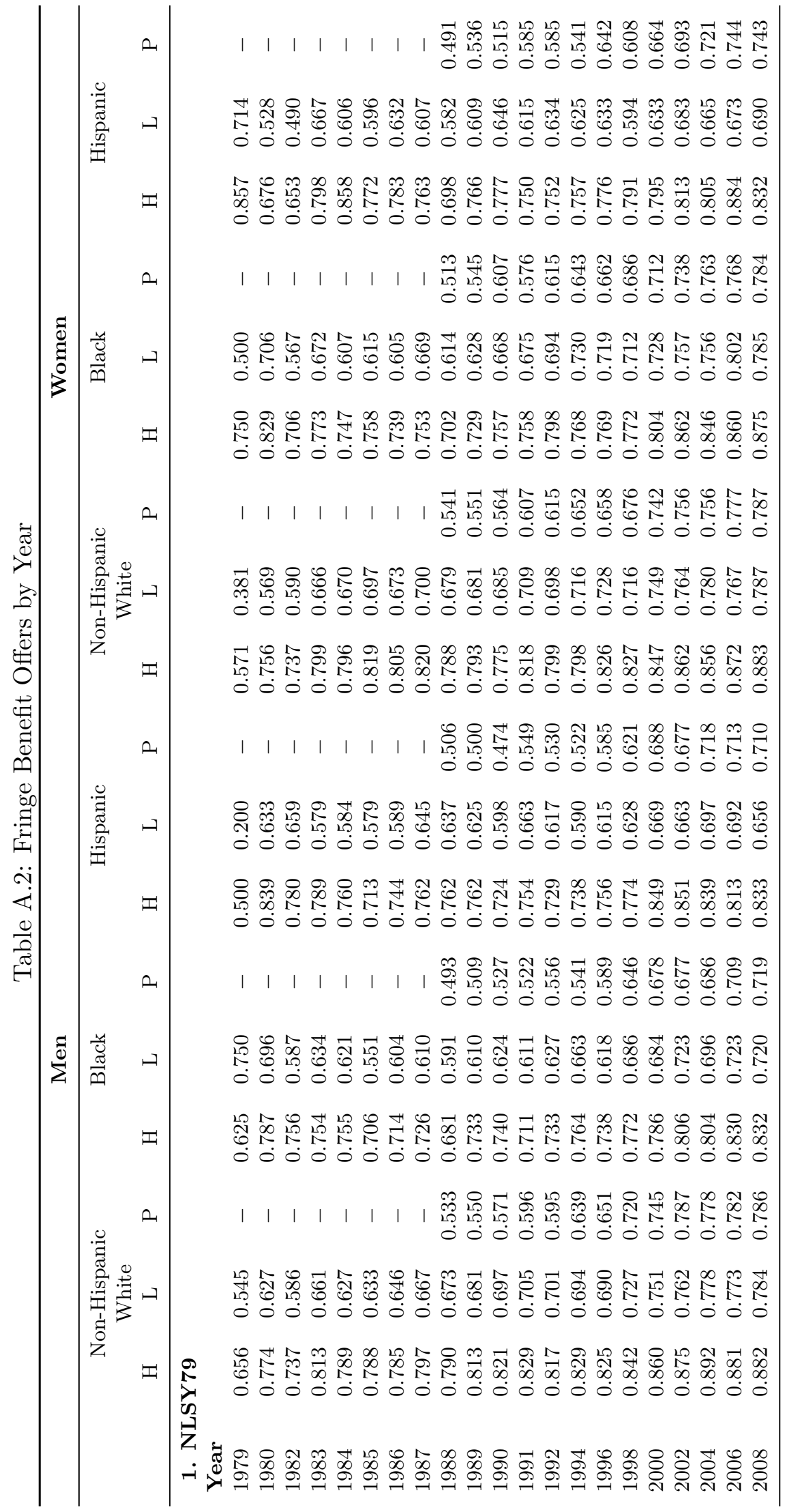

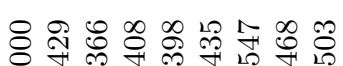

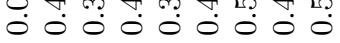

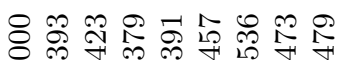
०० :

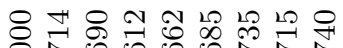
०००:0:0:0000



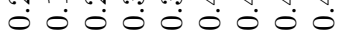

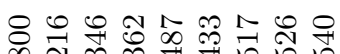

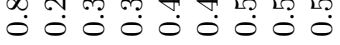

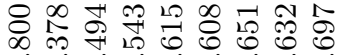

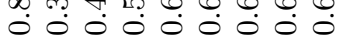

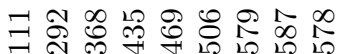
$\circ 00000000$

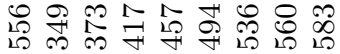

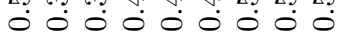

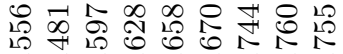
० 000000000

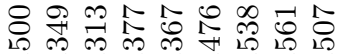
००

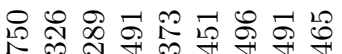

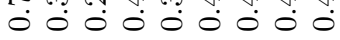

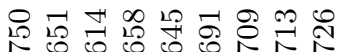
○: $0: 0: 0: 0.00$

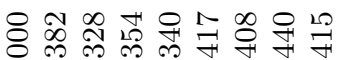

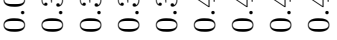

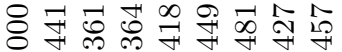
$\circ 00000000$

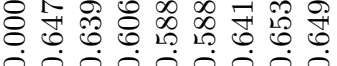
ผ

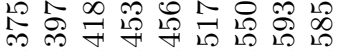
000000000


000000000

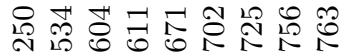
000000000 